\title{
Aplicação de Modelação Numérica e Física para o Estudo da Reabilitação e Proteção da Praia de Colwyn Bay, País de Gales, Reino Unido *
}

\author{
Application of Numerical and Physical Modelling to Study the Reabilitation and \\ Protection of Colwyn Bay Beach, Wales, U.K.
}

\author{
Filipa S. B. F. Oliveira ${ }^{\circledR,}{ }^{1}$, Maria Teresa Reis ${ }^{1}$, Paula Freire ${ }^{1}$, Maria Graça Neves ${ }^{1}$, Francisco Sancho ${ }^{1}$, \\ Luís G. Silva ${ }^{1}$, Manuel Clímaco ${ }^{1}$, Claudino M. Vicente ${ }^{1}$
}

\section{RESUMO}

Neste artigo descreve-se um estudo de avaliação da dinâmica costeira com vista à reabilitação e proteção da praia de Colwyn Bay, no País de Gales, Reino Unido, em avançado estado de erosão e degradação das suas funçôes recreativa e de proteção costeira. O estudo insere-se no âmbito de uma estratégia de gestão costeira baseada em defesa da acção do mar. Numa primeira fase, foi caracterizada a dinâmica da praia, através da avaliação da evolução morfológica tridimensional do topo e da face de praia, da composição sedimentológica recente da mesma zona, da hidrodinâmica da praia, com base em séries temporais de agitação marítima e nível do mar (incluindo as componentes de maré e sobrelevação de origem meteorológica), e da distribuição do transporte sedimentar longitudinal na zona ativa submersa. Numa segunda fase, de simulação e avaliação de soluçóes alternativas, baseadas numa estratégia de alimentação artificial, definiu-se e testou-se o perfil de enchimento, bem como soluçóes de longo prazo, algumas com estruturas de retenção/proteçáo (esporôes, esporóes em Y e quebra-mares destacados). Nestes testes foi utilizada a modelação numérica para a análise da morfodinâmica transversal da praia a curto prazo, no caso do perfil de enchimento, e da evoluçáo da linha de costa a longo prazo, no caso da forma plana da praia com e sem estruturas. As diversas metodologias de análise aplicadas e respetivos resultados são também descritos neste artigo com detalhe. Também no âmbito do teste de soluçôes de reabilitação da praia, foram realizados testes em modelo físico para análise da estabilidade e dos galgamentos para várias soluçóes alternativas do perfil transversal da defesa longitudinal aderente de enrocamento do extremo Este de Colwyn Bay. O estudo, com base na análise comparativa de soluções alternativas, permitiu definir o volume mínimo de alimentação artificial necessário à reabilitação e proteção da praia, qual a solução com melhor desempenho na retenção do enchimento da praia, e quais as características mais eficazes do perfil da defesa longitudinal (inclinação do talude do manto exterior, geometria do muro-cortina, geometria e permeabilidade da berma do coroamento) no que diz respeito à estabilidade do manto e aos galgamentos. Apresentam-se também recomendaçóes relativamente às necessidades de execução de uma análise custo-benefício das soluçóes de alimentação com melhor desempenho e de monitorização da futura praia, e recomendaçóes sobre aspetos adicionais a considerar no projeto de execução da defesa longitudinal.

Palavras-chave: Erosão Costeira, Alimentação Artificial, Estruturas Costeiras.

@- Autora correspondente

1 -Laboratório Nacional de EngenhariaCivil, Lisboa,Portugal.e-mails:foliveira@lnec.pt, treis@lnec.pt,pfreire@lnec.pt, gneves@lnec.pt, fsancho@lnec.pt, lgsilva@lnec.pt,mclimaco@lnec.pt, claudino.mvicente@gmail.com 


\section{ABSTRACT}

Colwyn Bay is a seaside holiday resort, located in the North Wales coastline of the United Kingdom, which faces the Irish Sea. It has an historic link with tourism, which drives the economy of the coastal region through the development of the town's frontage and associated coastal and marine environments. The study here described aimed to rehabilitate and protect Colwyn Bay beach, which is undergoing an advanced process of erosion and degradation of its recreational, bathing and coastal protection functions. Due to the notable reduction of the beach width and lowering of the beach berm and face, seawall overtopping and consequent flooding of the promenade occur frequently under sea storm events. For this reason, the Conwy County Borough Council decided on the development of a coastal defence strategy plan for Colwyn Bay. The present paper describes the study performed. The characterization of the beach dynamics was performed in a first stage. It was evaluated the three-dimensional evolution of the beach face and backshore, the recent sedimentologic contents of the same zone, the beach hydrodynamics, based on a wave climate series at three inshore points in front of the beach and on the analysis of a tidal and a surge levels series, the evaluation of the beach submerged active zone and the evaluation of the cross-shore distribution of the sediment drift. In a second stage, a stage of simulation and evaluation of alternative solutions based on a beach nourishment strategy, it was defined and tested the recharged beach profile and tested the long-term solutions, some of them with retention/protection structures (groynes, fishtail groynes and detached breakwaters). These tests were based on numerical modelling of the short-term cross-shore morphodynamics in the case of the recharged beach profile, and on numerical modelling of the long-term shoreline evolution in the case of the beach planform with and without structures. The several methodologies of analysis applied and the respective results are described in detail. Also within the scope of testing beach rehabilitation solutions, physical modelling was performed of the armour stability and wave overtopping for the several alternative cross-sections considered for the new linear defence at the Eastern frontage of Colwyn Bay. The main conclusions of the study, achieved through the comparative analysis of alternative solutions, were on the minimum volume of artificial beach nourishment required for the beach rehabilitation and protection, on the solution with best performance in retaining the beach recharge in the long-term, and on the most effective characteristics of the cross-section of the linear defence (armour slope, concrete wall geometry, geometry and permeability of the crest berm) concerning armour stability and wave overtopping. Recommendations regarding the need to execute a cost-benefit analysis for the beach nourishment solutions with best performance, monitoring the future beach and considering additional aspects for the design of the linear defence were pointed out.

Keywords: Coastal Erosion, Beach Nourishment, Coastal Structures.

\section{INTRODUÇÁO}

A praia de Colwyn Bay localiza-se na costa norte do País de Gales no Reino Unido (Figura 1). Possui valor histórico significtivo como estância balnear e valor económico, relevante para a população e administração local, como recurso turístico. Neste contexto, Colwyn Bay é conhecida pelo desenvolvimento urbanístico da sua frente marítima ao longo de uma extensão de linha de costa com cerca de $3,5 \mathrm{~km}$. No entanto, atualmente, esta praia sofre de notável erosão, que se traduz numa redução da largura de praia e num rebaixamento da berma e face de praia, e consequentemente, de acentuada degradação da maioria das infraestruturas marítimas existentes (Figura 2). Atualmente, em situaçóes de preia-mar, o Mar da Irlanda alcança o paredão (defesa longitudinal aderente) que limita a praia ao longo de toda a sua extensão longitudinal, provocando a degradação desta estrutura centenária (já reforçada no passado). Em situaçóes de tempestade, quando ocorrem ventos fortes e baixas pressóes atmosféricas, as elevadas alturas de onda e sobrelevação do nível do mar dão frequentemente origem a galgamentos que causam inundaçôes da estrada marginal adjacente à defesa longitudinal aderente, pondo em perigo pessoas, bens e infraestruturas. Em suma, a praia encontra-se em avançado estado de degradação das suas funçôes recreativa (como zona de lazer e uso balnear) e de proteção costeira, e a defesa longitudinal aderente encontra-se fragilizada estruturalmente e não garante proteçấo contra os galgamentos. Dada a situação, a autoridade local (Conwy
County Borough Council) decidiu desenvolver um plano de defesa costeira baseado no redimensionamento da defesa longitudinal aderente e na reabilitação e proteção da praia (CCBC, 2007). O estudo que aqui se descreve insere-se no âmbito de uma estratégia de gestão costeira baseada em defesa da acçáo do mar e teve como objetivo testar, analisar e avaliar soluçóes alternativas de reabilitação e proteção da praia baseadas numa estratégia de alimentação artificial e soluçóes alternativas estruturais para melhoria da defesa longitudinal aderente. Neste contexto, realizouse a caracterização da dinâmica da praia para, com base no seu conhecimento, testar soluçóes alternativas de longo prazo baseadas em alimentação artificial com e sem estruturas de retenção/proteção (esporóes, esporóes em Y e quebra-mares destacados). O teste destas soluçóes baseou-se em modelação numérica da morfodinâmica de curto prazo e da evolução da linha de costa a longo prazo. Procedeu-se também ao teste de soluçóes alternativas do perfil transversal da defesa longitudinal aderente recorrendo a modelação física realizada em canal de ondas, para verificação da sua estabilidade e dos galgamentos.

$\mathrm{Na}$ próxima secção descrevem-se os métodos aplicados na caracterização da dinâmica da praia, na análise de soluções alternativas para a reabilitação e proteção da praia e na análise de soluçôes alternativas para a melhoria da defesa aderente. Os principais resultados são apresentados na secção seguinte e é com base na sua análise crítica que se conclui sobre a eficiência das soluçôes e se fazem recomendaçóes relativamente às soluçôes a implementar. 


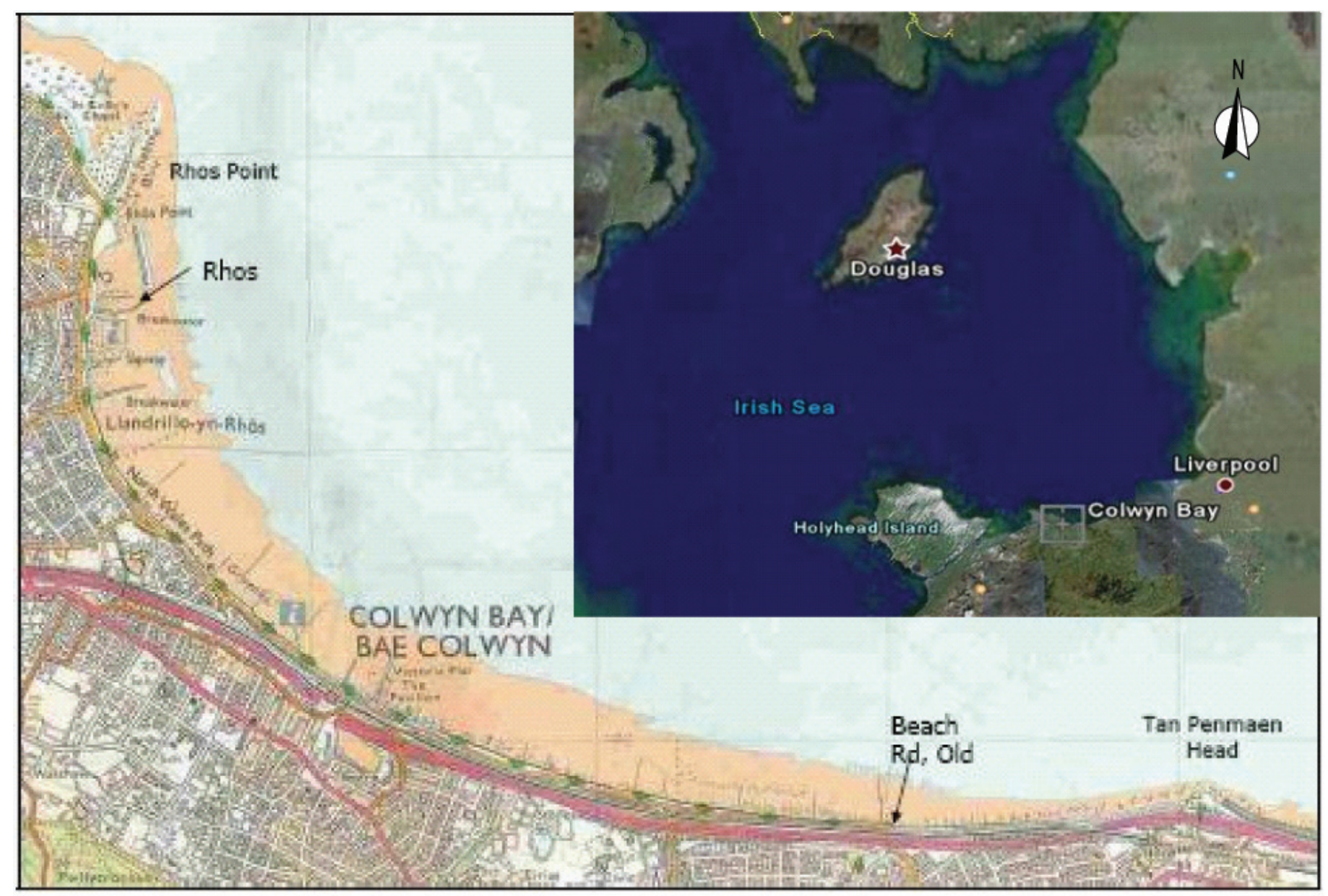

Figura 1. Localização da área de estudo.

Figure 1. Location of the study area.
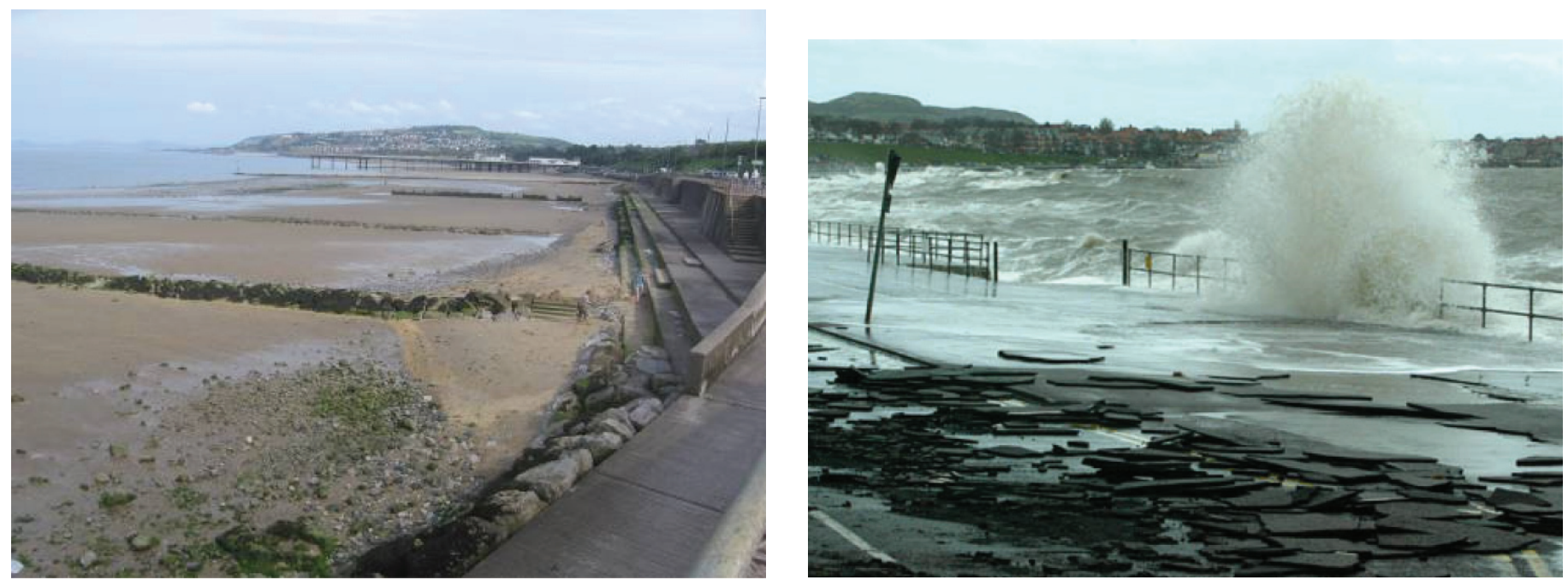

Figura 2. Estado de degradação da praia e do paredão: a) praia em condiçóes de baixa-mar e b) galgamento do paredão.

Figure 2. Beach and existing seawall damages: a) beach at low tide conditions and b) wave overtopping of the seawall. 


\section{MÉTODOS}

\subsection{Análise de dados e modelação numérica da praia}

\subsubsection{Caracterizaçáo da dinâmica hidro-sedimentar}

A caracterização da dinâmica da praia consistiu: a) na análise da evolução morfológica da face e berma de praia, b) na análise da composição sedimentológica das mesmas zonas, c) na análise do regime de agitação marítima (e em particular das tempestades), d) na análise do nível do mar (especificamente, da componente devida à maré astronómica e da componente devida à sobrelevação meteorológica) e e) na análise do transporte longitudinal na zona ativa submersa (faixa adjacente à linha de costa, do lado do mar, onde ocorre transporte sedimentar significativo na componente longitudinal). A metodologia aplicada, esquematizada na Figura 3, baseou-se num vasto conjunto de dados observados: levantamentos topo-hidrográficos desde 1956, fotografias aéreas de diversas datas, informaçáo sobre os sedimentos da face e berma de praia, uma série temporal de 19 anos de parâmetros de agitação marítima e uma série temporal de 15 anos do nível do mar.

Deforma sucinta, descreve-se seguidamente a metodologia aplicada:

a) A análise da evolução morfológica baseou-se em levantamentos topo-hidrográficos de diferentes datas, compreendidas entre 1956 e 2007, e incluiu os seguintes aspetos: a evolução da posição da linha de costa; a evolução tridimensional (3D) da face de praia; e a evolução do perfil transversal de praia. A evolução da posiçáo da linha de costa, isolinha correspondente à elevação igual a $0 \mathrm{~m}$ relativa ao Ordinance Datum Newlyn (ODN), foi determinada com base na ferramenta Digital Shoreline Analysis System (DSAS), que estende as funcionalidades do software ArcGIS (ESRI), permitindo a automatização de grande parte das tarefas relacionadas com a análise quantitativa da evolução da linha de costa (Thieler et al., 2009). As datas dos levantamentos analisados foram 1956, 1980, 1990, 2002 e 2007. A evoluçáo 3D da face da praia incluiu a sua totalidade, desde o limite do paredão $(2,5 \mathrm{~m} \mathrm{ODN})$ até à cota aproximada de $-1,5 \mathrm{~m}$ ODN, e baseou-se na comparação dos modelos digitais de elevação construídos com base em levantamentos topográficos datados de Outubro de 2001 a Novembro de 2007 (aproximadamente 2 levantamentos anuais). A zona de análise consistiu na área comum dos levantamentos, correspondendo a uma área total de 433,8 x $10^{3} \mathrm{~m}^{2}$. Obtiveram-se balanços volumétricos e taxas de erosão e assoreamento para cada período de comparaçáo. A evolução do perfil transversal da praia baseou-se em dois tipos de dados: levantamentos históricos de 103 perfis de praia datados entre 1956 e 1995; e levantamentos topográficos mais recentes, de Novembro de 1997 a Maio de 2009. Foram avaliados vários indicadores morfológicos sobre a evolução de cada perfil, designadamente a variação média, máxima e a taxa de variaçâo da elevação da face de praia na base da defesa longitudinal aderente. Dos levantamentos mais recentes foram analisados os datados de Outubro de 2001 a Maio de 2009 (2 levantamentos por ano), nomeadamente 5 perfis transversais (por

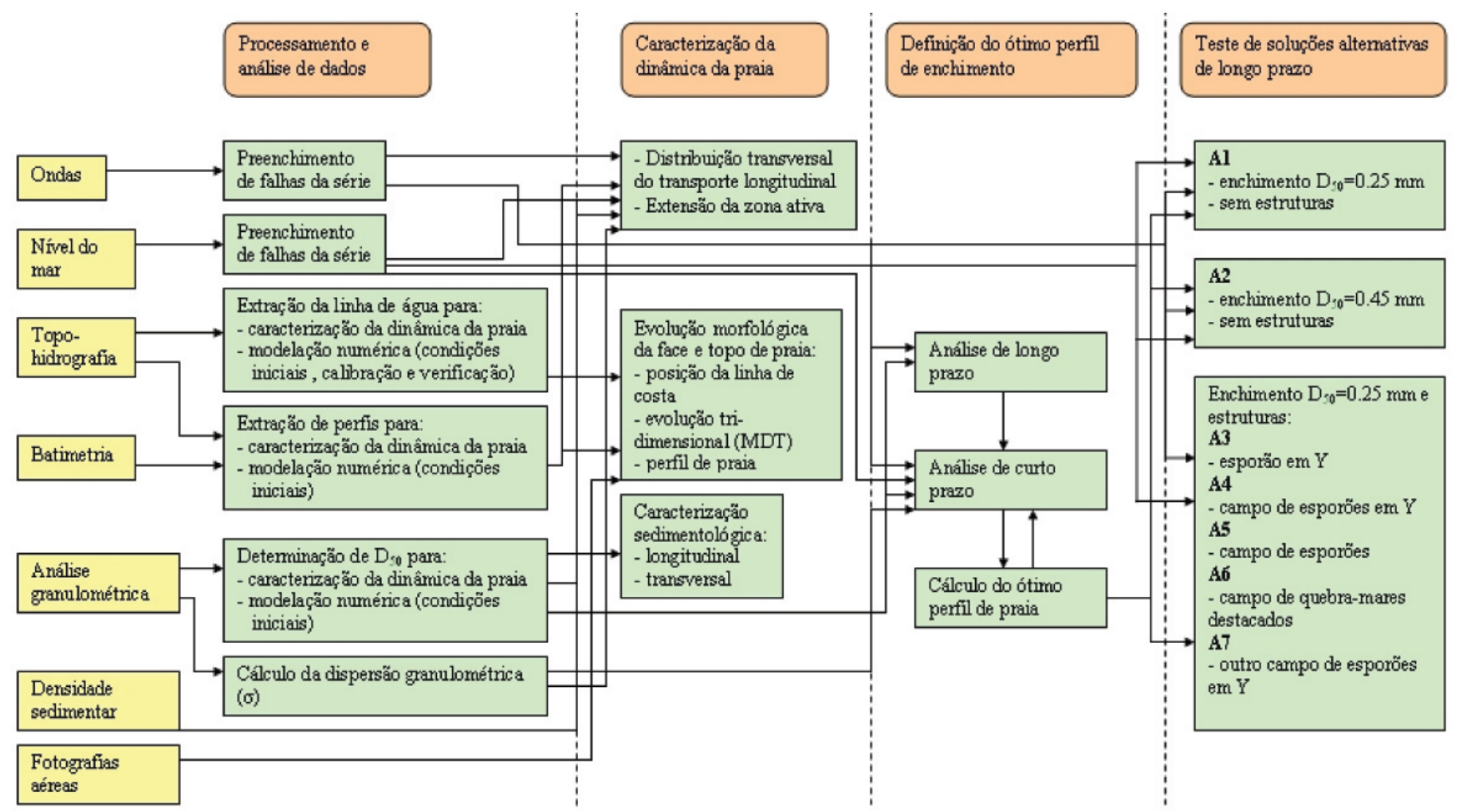

Figura 3. Esquema da metodologia aplicada para caracterização da dinâmica da praia e análise de soluçóes alternativas de reabilitação e proteção. Figure 3. Scheme of the methodology applied for the characterisation of the beach dynamics and analysis of alternative solutions for rehabilitation and protection. 
apresentarem melhor consistência nas direçóes), desde a defesa longitudinal até aproximadamente à elevação $-4 \mathrm{~m}$ ODN. Os parâmetros morfológicos analisados foram: largura da praia a diferentes níveis de referência $(0$, -2 e -3 m ODN); área da praia, estimada em cada perfil acima do $0 \mathrm{~m}$ ODN e entre 0 e $-2 \mathrm{~m} \mathrm{ODN}$; e volume subaéreo da praia, considerando que cada perfil tem uma extensão lateral igual à soma de metade da distância entre dois perfis consecutivos.

b) A análise da composição sedimentológica foi efetuada com base em sondagens curtas ao longo de 9 perfis (3 sondagens por perfil e 3 amostras por sondagem recolhidas às elevaçôes $1,5 \mathrm{~m}, 0,0 \mathrm{~m}$ e $-2,6 \mathrm{~m}$ ODN). Foram determinados os parâmetros diâmetro mediano, $\mathrm{D}_{50}$, e coeficiente de graduação, $\sigma$ (igual a $\left(\mathrm{D}_{84} / \mathrm{D}_{16}\right)^{0,5}$, em que $\mathrm{D}_{16}$ e $\mathrm{D}_{84}$ são os valores de diâmetro abaixo dos quais $16 \%$ e $84 \%$ da distribuição têm diâmetros inferiores, respetivamente). A densidade das partículas foi determinada para algumas amostras, assim como a composiçâo mineralógica da fração arenosa, que foi avaliada através de observaçáo à lupa binocular.

c) A análise da agitação marítima foi efetuada com base no processamento de três séries (correspondentes a três posiçóes ao largo em frente à praia: Oeste, Central e Este) de valores horários dos seguintes parâmetros: altura de onda significativa, $\mathrm{Hs}$, período médio da onda, Tz, e direção média da onda, $\theta$. Estas séries foram obtidas através de um modelo de reconstituição (bindcast) da agitação marítima forçado pelo vento ocorrido ao longo de 19,5 anos, entre 1986/10/01 e 2006/03/31. Verificou-se que as falhas (lacunas) das séries de agitação marítima resultantes da falta de dados de vento (ou vento nulo), correspondentes a $13 \%$ dos dados, se encontravam bem distribuídas ao longo do ano. Tendo em vista a reconstituição das séries, essas falhas foram colmatadas da seguinte forma: por valores interpolados, no caso do intervalo de falha ser inferior a um dia; e pelos valores médios diários anuais (ou considerando todos os registos naquele dia em todos os anos) no caso de falhas com duração superior a um dia. A caracterização do regime médio foi feita em classes de $0,25 \mathrm{~m}$ para $\mathrm{Hs}, 1 \mathrm{~s}$ para $\mathrm{Tz}$ e $10^{\circ}$ para $\theta$.

d) A análise do nível do mar baseou-se na série temporal de dados do marégrafo de Llandudno (a cerca de 8 km a Oeste de Colwyn Bay), entre Maio de 1994 e Dezembro de 2008. Os dados contêm: níveis de água medidos a cada 15 minutos (referidos ao Admiralty Chart Datum Reference (ACD), cuja relação com ODN é $\mathrm{ACD}=\mathrm{ODN}-3.85 \mathrm{~m}$ ), e os resíduos calculados pela diferença entre os valores medidos e os níveis de maré previstos pelo BODC (British Oceanographic Data Centre). As falhas encontradas nos registos, por ano, oscilam entre aproximadamente $45 \%$ (em 1994) e $0 \%$ (ano completo, em 2005). O período máximo com falhas é de 3,5 meses. Tendo em vista a construção de uma série temporal contínua de nível do mar com início em 1987/01/01 (início do período considerado para a agitação marítima) aplicou-se a seguinte metodologia: i) calcularam-se as constituintes de maré utilizando o software "T_TIDE" (Pawlowicz et al., 2002), com base nos dados do período entre 1995/01/01 e 2000/12/31 (6 anos); ii) reconstituiu-se a série de níveis de maré para o período completo de 19 anos com início em 1987/01/01, a partir das constituintes de maré; iii) adicionou-se a sobrelevação registada na série original aos valores previstos para o nível de maré (usaram-se exatamente os valores registados para o período entre 1995 e 2005, e para o período entre 1987 e 1994 utilizaram-se os resíduos medidos em outros anos).

e) A análise do transporte longitudinal na zona ativa submersa foi efetuada com base na aplicação do modelo Litdrift (DHI, 2008) para os 19 anos completos (19872005) das séries de agitação marítima e nível do mar (esta última construída conforme descrito acima). Foi aplicado um modelo numérico do tipo perfil (2D-vertical), baseado nos principais processos físicos costeiros determinantes para o transporte sedimentar (em suspensão e de fundo) na zona de rebentação, que inclui a variação granulométrica (através do parâmetros $D_{50}$ e $\sigma$ ) dos sedimentos na direção transversal da praia. O cálculo do transporte longitudinal num perfil representativo da morfologia da praia (aproximadamente no centro da zona de estudo) foi antecedido por uma análise de sensibilidade aos parâmetros sedimentológicos, uma vez que se verificou a existência de grande variabilidade do valor destes parâmetros, assim como a existência de afloramentos argilosos, na face de praia. Aplicou-se um espaçamento horizontal de $2 \mathrm{~m}$ ao longo do perfil transversal e a cada ponto associaram-se os respetivos parâmetros sedimentológicos (extrapolados com base nos resultados das amostras superficiais e nas conclusóes da análise de sensibilidade realizada). Através da aplicaçáo do modelo determinou-se o transporte sedimentar instantâneo, de $3 \mathrm{em} 3$ horas, em cada ponto do perfil, para os 19 anos em apreço. Com base neste resultado calculou-se a capacidade de transporte sedimentar em cada sentido longitudinal da praia (Este e Oeste) e a extensão da zona onde ocorre 90 e $95 \%$ do transporte (assim como a correspondente profundidade). Com base nestes resultados também foi possível concluir sobre outros parâmetros de caracterização da dinâmica sedimentar da praia, tais como a variabilidade anual e sazonal do transporte longitudinal.

\subsubsection{Soluçôes alternativas}

Tendo em vista definir soluçôes alternativas de reabilitação e proteção baseadas numa estratégia de alimentação artificial, implementou-se uma metodologia constituída por duas partes principais, que tiveram por objetivo: a primeira, a definição do perfil de enchimento; e a segunda, o teste de soluçốes de longo prazo, algumas com estruturas de retenção/ proteção (esporōes, esporóes em Y e quebra-mares destacados) (Figura 3).

$\mathrm{O}$ dimensionamento do perfil de enchimento e, consequentemente, a estimativa do volume de enchimento, foi baseado: i) no conceito de perfil de equilíbrio, para a face e zona submersa ativa; e ii) na resiliência do perfil em condiçóes de tempestade, para a berma. Neste caso de estudo, foi considerado o efeito da grande amplitude de maré (entre 4 a $8 \mathrm{~m}$ ) na geometria do perfil de longo prazo, 
tendo sido usado um perfil de equilíbrio de dois-declives baseado no método "2S-EBP" (2 Slope-Equilibrium Beach Profile) de Bernabeu et al. (2003). Este método incorre na determinação de 4 coeficientes de forma da praia que são função do número adimensional de queda das partículas, $\Omega=H_{s} / w T$ (onde $\mathrm{T}$ foi considerado o período médio da onda, Tz), que por sua vez contém a dependência da dimensão característica dos sedimentos através da velocidade de queda, $w$. Determinaram-se perfis de equilíbrio para 3 diâmetros característicos dos sedimentos: $\mathrm{D}_{50}=0,25,0,5$ e $0,75 \mathrm{~mm}$. A cota do topo do perfil de praia foi dimensionada em função do nível máximo de água ou do nível de água excedido somente uma pequena percentagem de tempo.

$\mathrm{O}$ dimensionamento da berma foi baseado em: i) condicionamentos económicos (considerando que quanto mais estreita for a berma menor será o volume de recarga), ii) necessidade de uma largura razoável para utilização balnear e de recreio (apesar de também vir a ser condicionada pelas alteraçóes da forma plana a longo prazo) e iii) manutenção de uma largura mínima de segurança para evitar a ação direta da agitação sobre o paredão em condiçôes de tempestade. Foi no âmbito desta última condição que se testou a resiliência do perfil em condiçóes de tempestade.

Considerando uma largura de berma de $50 \mathrm{~m}$ e a dimensão das partículas sedimentares disponíveis para o enchimento (informação obtida através da prospeção da área de empréstimo), que se associou à respetiva configuração de perfil 2S-EBP, estabeleceu-se um conjunto de casos de teste (Tabela 1). Simulou-se a evolução do perfil de enchimento sob ação erosiva para estes casos. Aplicou-se o modelo numérico Litprof (DHI, 2008), 2D-vertical, do tipo modelo de perfil, baseado nos processos físicos litorais de morfodinâmica de curto prazo. Testaram-se as tempestades ocorridas em Fev/1990 e Dez/1990 (Figura 4). A primeira correspondeu ao período mais longo de ondas consecutivas com $\mathrm{Hs}$ superior a $3 \mathrm{~m}$ da série de 19 anos de agitação marítima. A segunda correspondeu ao período em que o nível do mar alcançou níveis mais elevados devido à sobrelevação (gerada por baixas pressões meteorológicas). Nos testes 1-5 a berma foi considerada plana ao nível $4 \mathrm{~m}$ ODN. Nos testes 6-7 a berma foi considerada com declive 1:100, desde o nível $5 \mathrm{~m}$ ODN, junto ao paredão, até ao nível 4,5 m ODN.

Tabela 1. Condiçóes geomorfológicas e hidrodinâmicas dos testes de erosão a curto prazo.

Table 1. Geomorphologic and hydrodynamic conditions of the short term erosion tests.

\begin{tabular}{cccc}
\hline Teste $^{\boldsymbol{o}}$ & Condiçóes sedimentológicas $\boldsymbol{D}_{50}(\mathbf{m m}) ; \boldsymbol{\sigma}(-)$ & Perfil de enchimento & Tempestade \\
\hline 1 & 0,$25 ; 1,72$ & $2 \mathrm{~S}-\mathrm{EBP}+$ berma horizontal & $\mathrm{Dez} / 90$ \\
\hline 2 & 0,$75 ; 5,01$ & $2 \mathrm{~S}-\mathrm{EBP}+$ berma horizontal & $\mathrm{Dez} / 90$ \\
\hline 3 & 0,$75 ; 2,39$ & $2 \mathrm{~S}-\mathrm{EBP}+$ berma horizontal & $\mathrm{Dez} / 90$ \\
\hline 4 & 0,$25 ; 1,72$ & $2 \mathrm{~S}-\mathrm{EBP}+$ berma horizontal & $\mathrm{Fev} / 90$ \\
\hline 5 & 0,$45 ; 2,10$ & $2 \mathrm{~S}-\mathrm{EBP}+$ berma horizontal & $\mathrm{Fev} / 90$ \\
\hline 6 & 0,$25 ; 1,72$ & Declive constante $(1: 35)+$ berma inclinada $(1: 100)$ & $\mathrm{Fev} / 90$ \\
\hline 7 & 0,$45 ; 2,10$ & Declive constante $(1: 30)+$ berma inclinada $(1: 100)$ & $\mathrm{Fev} / 90$ \\
\hline
\end{tabular}

a)

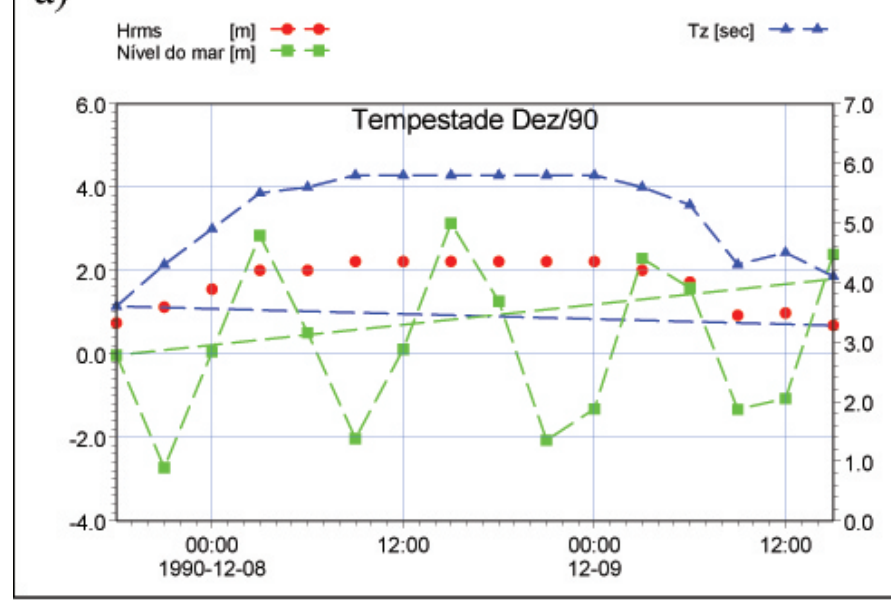

b)

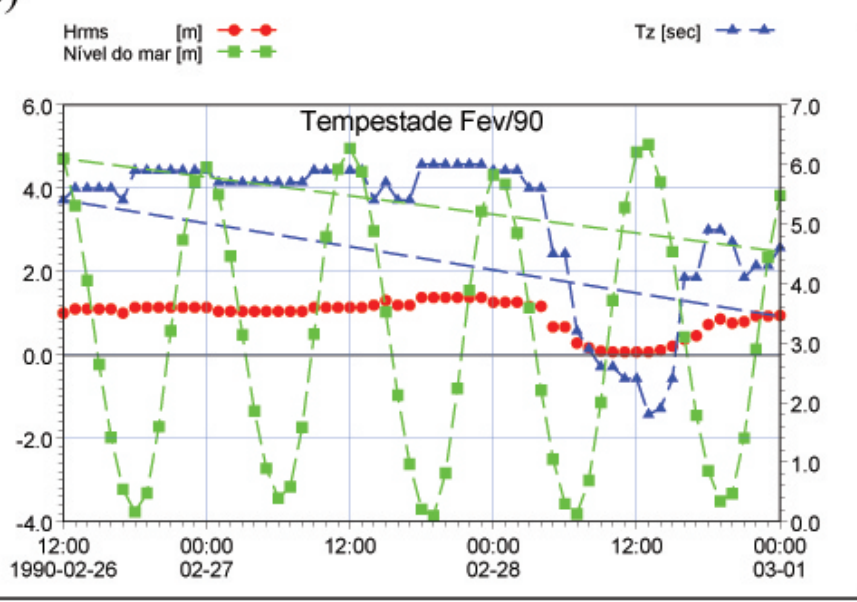

Figura 4. Características das tempestades de a) Dez/90 e b) Fev/90: parâmetros Hrms e nível do mar (esquerda); e Tz (direita).

Figure 4. Characteristics the a) Dec/90 and b) Feb/90 storms: parameters Hrms and sea level (left); and Tz (right). 
O teste das soluçóes alternativas de longo prazo foi baseado na aplicação de dois modelos numéricos de evolução da linha de costa, os modelos Litmod (Vicente, 1991; Vicente e Clímaco, 2003) e Litline (DHI, 2008). A aplicaçấo dos dois modelos deve-se ao facto deles terem diferentes abordagens metodológicas e consequentemente diferentes capacidades e limitações. Por exemplo, o Litline simula a variação instantânea do nível do mar devida à maré e o Litmod não (foi aplicado para o nível médio do mar); o Litmod simula o efeito de esporóes em forma de $\mathrm{Y}$ e o Litline não. A aplicação de ambos permitiu testar um conjunto alargado de soluçóes de reabilitação.

A primeira fase da metodologia de modelação das soluções alternativas consistiu na calibração dos modelos. Foi realizada para o período Out/2001 - Jul/2005, porque o primeiro levantamento completo da zona foi realizado em Out/2001 e a série temporal de agitação marítima termina em 2005. As linhas de costa (nível $0 \mathrm{~m}$ ODN) utilizadas no processo de calibração foram: a linha de Out/2001, como linha inicial; e as quatro linhas Out/2002, Jul/2003, Maio/2004 e Jul/2005, como linhas de verificação. Foram considerados os perfis de praia de Out/2001 em consonância com a data da linha de costa inicial. Considerou-se o gradiente (variação espacial) de energia incidente na praia ao longo da direção longitudinal através da utilização dos três climas de agitação (Oeste, Central e Este) em ambos os modelos. No modelo Litline utilizaram-se espaçamentos de células iguais a $40 \mathrm{e}$ $2 \mathrm{~m}$ ao longo da linha de base (linha de referência do modelo) e do perfil, respetivamente, e consideraram-se as seguintes condiçóes fronteira: zona ativa bloqueada até ao quebra-mar destacado (com difração) na fronteira Oeste, e zona ativa totalmente aberta na fronteira Este. No modelo Litmod utilizou-se a fórmula de Kamphuis (Kamphuis, 1991) para o cálculo do transporte sólido litoral, um passo de cálculo de 0,01 dia e células com $40 \mathrm{~m}$ de comprimento ao longo da linha de base. As condiçóes fronteira consistiram: na taxa de transporte imposta na fronteira Este e na taxa de transporte a Oeste resultante do processo de evolução morfológica (erosão/acreçáo) observado entre fronteiras.

A segunda fase da metodologia para modelação das soluçôes alternativas consistiu no teste de duas soluções de alimentação artificial sem estruturas de proteção. Testou-se a evolução (para os 19 anos da série de agitação marítima) do enchimento da praia para dois tipos de sedimentos e respetivos perfis (2S-EBP e berma com declive 1:100 entre os níveis 5 e 4,5 m ODN). Estas soluçóes corresponderam a: 3,3 milhões de $\mathrm{m}^{3}$ de areia com $\mathrm{D}_{50}=0,25 \mathrm{~mm}$ (área de enchimento 1,6 milhóes de $\mathrm{m}^{2}$ ); e 2,2 milhóes de $\mathrm{m}^{3}$ de areia com $\mathrm{D}_{50}=0,45 \mathrm{~mm}$ (área de enchimento 1,3 milhóes de $\mathrm{m}^{2}$ ).

A terceira fase da metodologia para modelação das soluções alternativas consistiu no teste de soluções de alimentação com estruturas de proteçấo, tais como esporôes, esporôes em $\mathrm{Y}$ e quebra-mares destacados. O objetivo foi analisar o efeito das estruturas implementadas na retenção do volume de areia depositado na praia.

\subsection{Modelaçáo física da defesa aderente}

Nesta secção descrevem-se aspectos de modelação física relacionados com a análise da estabilidade e dos galgamentos das várias soluçóes alternativas do perfil transversal da defesa longitudinal aderente de enrocamento, que foi inicialmente pensada para ser utilizada no extremo Este de Colwyn Bay. Descreve-se a configuraçáo do modelo físico no que diz respeito às instalaçốes de ensaio, à escala do modelo, aos perfis transversais, aos fundos do modelo, ao programa de ensaios e à avaliação da estabilidade e dos galgamentos dos perfis.

\subsubsection{Instalaçóes de ensaio e escala do modelo}

Realizaram-se ensaios com vista à análise da estabilidade e dos galgamentos, em modelo físico bidimensional, num canal de ondas irregulares, com cerca de $50 \mathrm{~m}$ de comprimento, $1,6 \mathrm{~m}$ de largura e 1,2 $\mathrm{m}$ de profundidade (largura e profundidade úteis de $0,8 \mathrm{~m}$ ) (Reis et al., 2010). Utilizou-se um batedor de pistão com um sistema de absorção ativa da reflexão, AWASYS (Troch, 2005), controlado pelo software SAM (Capitão, 2002).

Os modelos foram construídos e explorados de acordo com a semelhança de Froude, tendo sido utilizada a escala geométrica de 1:25. Esta escala foi selecionada de maneira a garantir que os principais aspetos da interação ondaestrutura (reflexão, dissipação e transmissão, especialmente por galgamento), eram bem reproduzidos no modelo, eram evitados efeitos de escala significativos, especialmente no que se refere à reprodução da rebentação e do escoamento nos mantos da estrutura, e as condiçóes de teste definidas podiam ser reproduzidas na instalaçáo de ensaio com os recursos disponíveis (Hughes, 1993; De Rouck et al., 2005).

\subsubsection{Perfis transversais e fundos do modelo}

Foram construídas e testadas oito alternativas para o perfil transversal da defesa longitudinal aderente de enrocamento, denominadas Alternativas 1 a 8 . A Tabela 2 apresenta as principais características da Alternativa 1 e as diferenças desta para as restantes alternativas ( 2 a 8$)$. As oito alternativas diferiam principalmente na inclinaçáo do talude do manto exterior, na geometria e permeabilidade da berma do coroamento e na geometria do muro-cortina. A Alternativa 1 foi desenvolvida a partir do perfil transversal preliminar que foi identificado no plano de defesa costeira (CCBC, 2007) e da avaliação empírica do seu desempenho relativamente aos galgamentos. As alternativas subsequentes foram testadas para avaliar o impacto provocado pela alteração de diferentes características da estrutura. A Figura 5 apresenta os perfis transversais das Alternativas 1, 5, 7 e 8 .

No modelo, os fundos em frente ao local de implantaçáo da defesa longitudinal aderente foram reproduzidos por intermédio de um fundo fixo, desde o pé do talude da estrutura até ao nível de $-0,164 \mathrm{~m}$, o que correspondia no protótipo ao nível de $0 \mathrm{~m}$ ACD $(-4,1 \mathrm{~m}$ ODN, Figura 6). $\mathrm{O}$ fundo foi reproduzido por duas rampas de diferente inclinação: 1:50 nos $5 \mathrm{~m}$ (125 m no protótipo) existentes imediatamente em frente à estrutura e 1:100 nos restantes $4,4 \mathrm{~m}$ (110 m no protótipo). 
Tabela 2. Características principais da Alternativa 1 e diferenças entre estas e as características das Alternativas 2 a 8.

Table 2. Main characteristics of Alternative 1 and corresponding differences for Alternatives 2 to 8.

\begin{tabular}{|c|c|c|c|c|c|c|c|c|c|}
\hline & & \multirow{3}{*}{$\begin{array}{c}\text { Caracteristicas Principais } \\
\text { da Alt. } 1 \\
\end{array}$} & & & & & & & \\
\hline & & & \multicolumn{7}{|c|}{ Diferenças Relativas à Alt. 1} \\
\hline & & & Alt. 2 & Alt. 3 & Alt. 4 & Alt. 5 & Alt. 6 & Alt. 7 & Alt. 8 \\
\hline \multicolumn{2}{|l|}{ Geral } & - defesa frontal aderente em talude & & & & & & & \\
\hline $\begin{array}{l}\text { Manto } \\
\text { Principal }\end{array}$ & $\begin{array}{l}\text { - talude: } \\
\text { - camadas: } \\
\text { - largura da berma do coroamento: } \\
\text { - cota da berma do coroamento: }\end{array}$ & 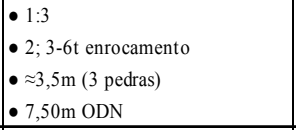 & & $\bullet 1: 2,5$ & $\bullet 1: 2,5$ & $\begin{array}{l}\bullet 1: 2,5 \\
\bullet \approx 11,47 \mathrm{~m} \text { (10 pedras) } \\
\end{array}$ & $\begin{array}{l}\bullet \approx 4,70 \mathrm{~m} \text { (4 pedras) } \\
-8,00 \mathrm{~m} \text { ODN } \\
\end{array}$ & $\begin{array}{l}\bullet \sim 4,70 \mathrm{~m} \text { (4 pedras) } \\
\bullet 9,00 \mathrm{~m} \text { ODN } \\
\end{array}$ & $\bullet \approx 4,70 \mathrm{~m}$ (4 pedras) \\
\hline \multicolumn{2}{|l|}{ Filtros } & - $300 \mathrm{~kg}$ - $1 \mathrm{t}$ enrocamento & & & & & & & \\
\hline Pé do Talude & $\begin{array}{l}\text { - cota: } \\
\text { - camada superior: } \\
\text { - camada inferior: }\end{array}$ & $\begin{array}{l}\bullet \approx-0,65 \mathrm{~m} \text { ODN } \\
-2 \text { pedras }(3-6 \mathrm{t}) \\
-3 \text { pedras }(3-6 \mathrm{t} ; \approx 3,5 \mathrm{~m} \text { de largura) }\end{array}$ & & & & & $\bullet \approx-0,61 \mathrm{~m} \mathrm{ODN}$ & 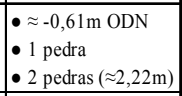 & $\begin{array}{l}\text { - } 1 \text { pedra } \\
\bullet 2 \text { pedras }(\approx 2,3 \mathrm{~m}) \\
\end{array}$ \\
\hline $\begin{array}{l}\text { Laje de Betão } \\
\text { (coroamento) }\end{array}$ & $\begin{array}{l}\text { - cota: } \\
\text { - talude: } \\
\text { - largura: } \\
\end{array}$ & \begin{tabular}{|l|}
$\bullet \approx 7,00 \mathrm{~m}$ ODN (no muro-cortina) \\
$\bullet 1: 40$ \\
$\bullet 4,5 \mathrm{~m}$
\end{tabular} & & $\bullet 7,97 \mathrm{~m}$ & $\bullet 7,97 \mathrm{~m}$ & Não existente & Não existente & Não existente & \\
\hline Muro-Cortina & $\begin{array}{l}\text { - tipo: } \\
\text { - cota de coroamento: }\end{array}$ & \begin{tabular}{|l} 
- secção retangular \\
• $8,00 \mathrm{~m}$ ODN \\
\end{tabular} & $\bullet 8,50 \mathrm{~m}$ ODN & & $\bullet 8,50 \mathrm{~m}$ ODN & $\bullet 8,50 \mathrm{~m}$ ODN & $\begin{array}{l}\text { - } \text { muro deflector } \\
\text { - 9,00m ODN }\end{array}$ & $\begin{array}{l}\text { - } \text { muro deflector } \\
-10,00 \mathrm{~m} \text { ODN } \\
\end{array}$ & \begin{tabular}{|l} 
- muro deflector \\
$\bullet 8,15 \mathrm{~m}$ ODN \\
\end{tabular} \\
\hline
\end{tabular}
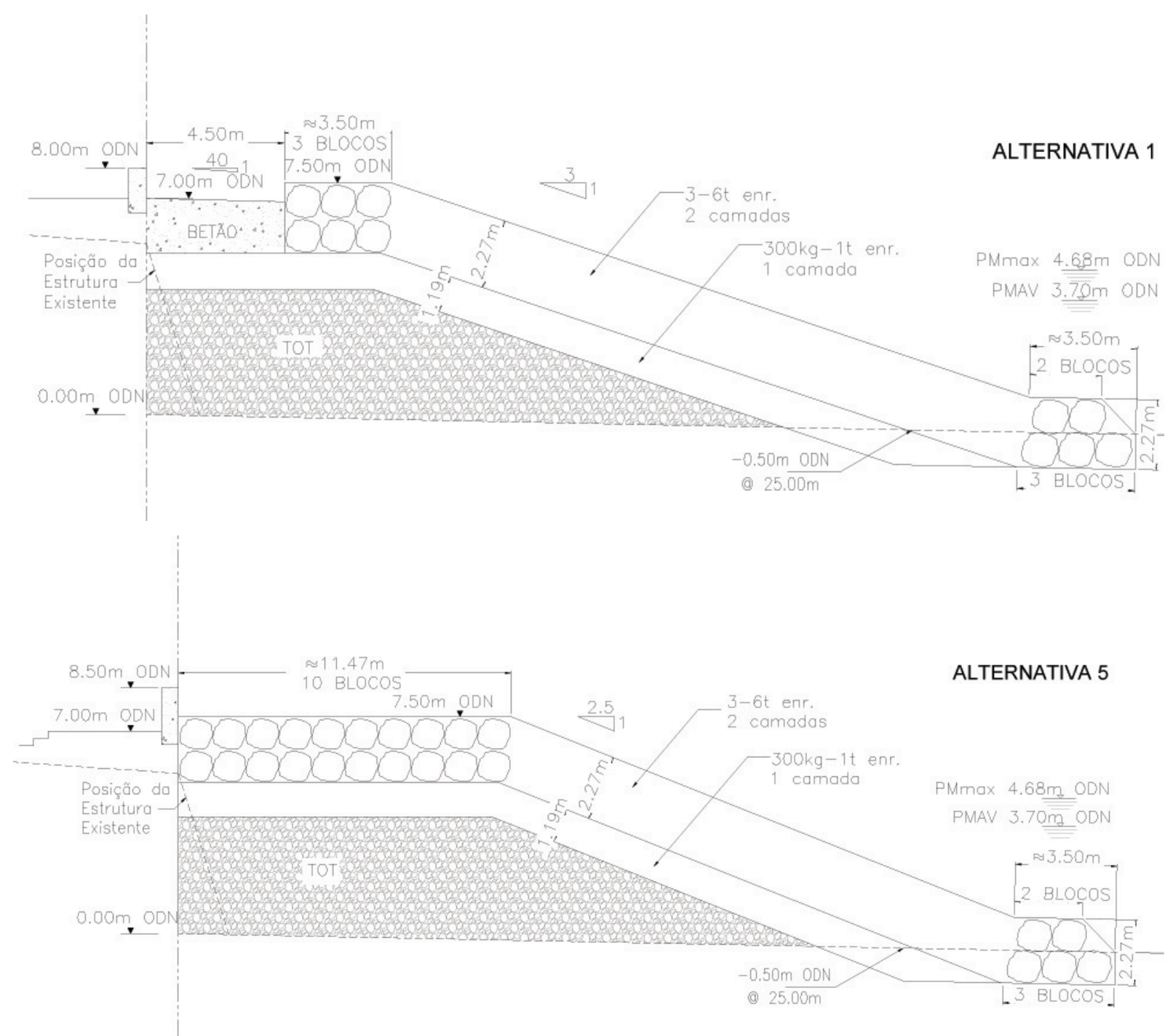

Figura 5. Continua na próxima página.

Figure 5. Continues in the next page. 


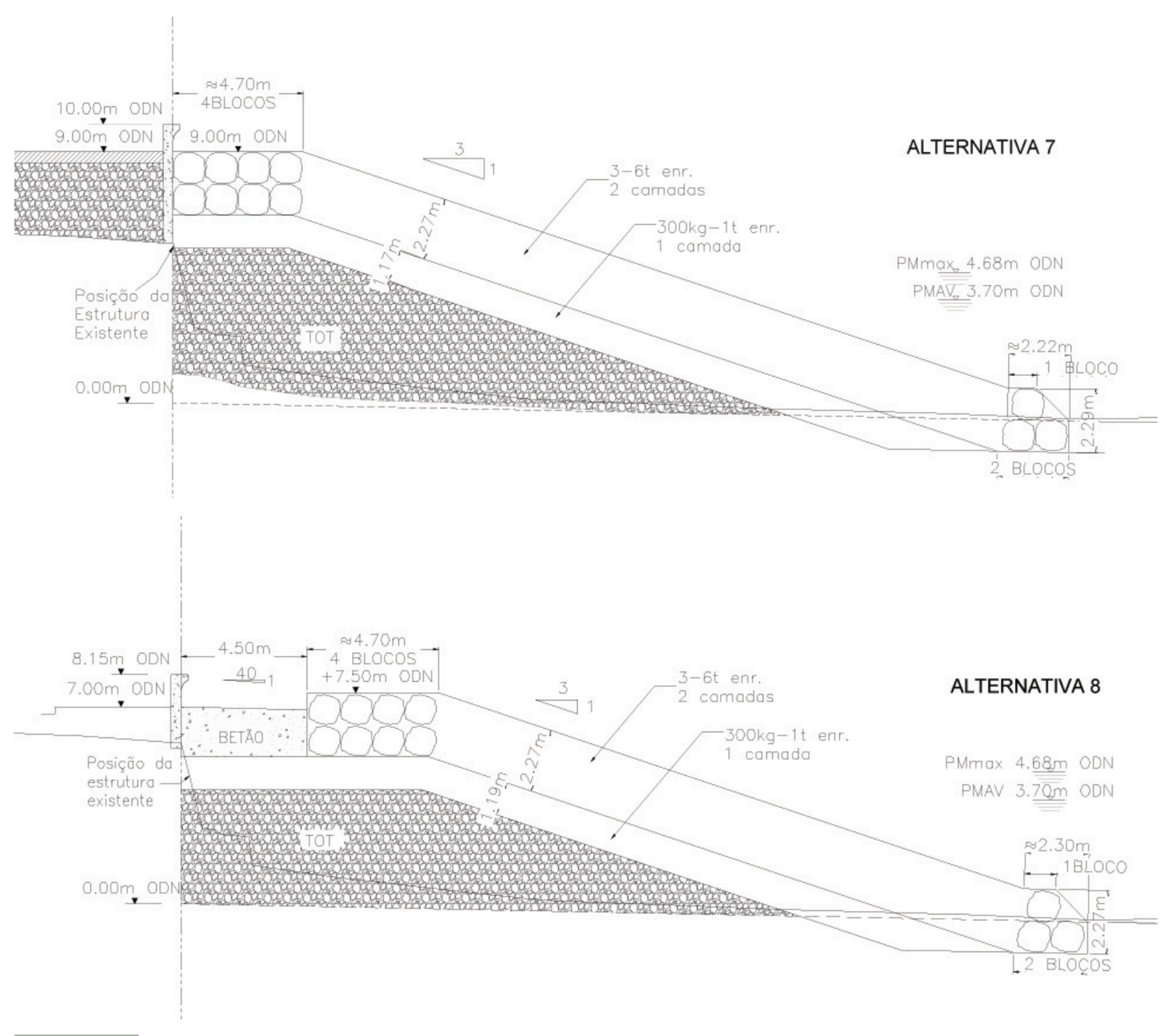

Figura 5. Perfil transversal das Alternativas 1, 5, 7 e 8.

Figure 5. Cross-sections of Alternatives 1, 5, 7 and 8.

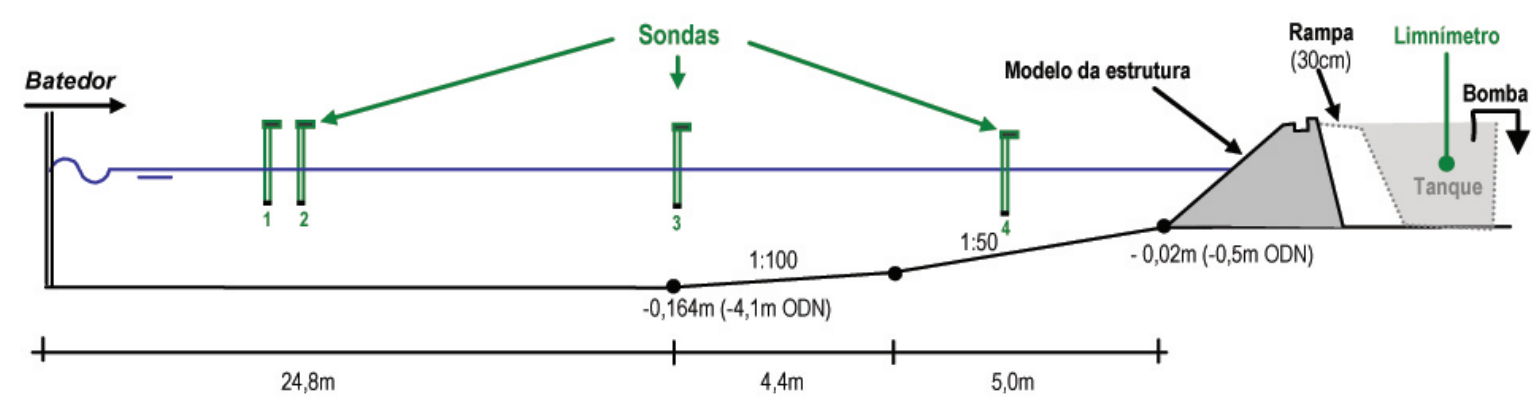

Figura 6. Representação esquemática do canal de ondas onde foram realizados os ensaios, do modelo do molhe e da localização do equipamento de medição utilizado.

Figure 6. Sketch of wave flume, model breakwater and location of experimental equipment. 


\subsubsection{Programa de ensaios}

Para cada uma das alternativas propostas para o perfil transversal da defesa longitudinal aderente, o programa de ensaios especificava uma sequência de testes, realizados com ondas irregulares, com uma configuração espectral empírica de JONSWAP (com um fator de esbelteza, $\gamma=3,3$ ). A cada um deles correspondiam valores nominais pré-definidos de altura de onda significativa, $\mathrm{H}_{\text {os }}$, e período médio, $\mathrm{T}_{\text {om }}$, na batimétrica -4,1 m ODN, e um nível de maré (Tabela 3). Estas condiçóes resultaram de uma análise de probabilidade conjunta de ocorrência de ondas e marés realizada para a frente marítima de Conwy (HR Wallingford, 2004) e os níveis de maré tiveram em conta previsóes de futuras subidas do nível do mar indicadas nas atuais recomendaçóes da DEFRA (2006).

Os valores de $\mathrm{H}_{\text {os }}$ e $\mathrm{T}_{\text {om }}$ variaram entre $1,8 \mathrm{~m}$ e 4,0 m e 5,6 s e 8,6 s, respetivamente, abrangendo uma grande gama de condiçóes com períodos de retorno entre 1 e 200 anos, que incluíam os potenciais casos mais desfavoráveis de probabilidade conjunta que tinham sido identificados em estudos preliminares de avaliação empírica do galgamento. No total, foram realizados 96 testes, cada um deles com uma duração aproximada de 1000 ondas.

Para a medição da superfície livre, o canal foi equipado com quatro sondas de condutância (Figura 6). Foram colocadas duas sondas fixas (sondas 1 e 2) próximas do batedor, necessárias ao funcionamento do sistema de absorção ativa da reflexão. A terceira sonda (sonda 3) foi localizada no final da parte horizontal do canal. A quarta sonda (sonda 4) foi posicionada em frente à estrutura. Os sinais provenientes das sondas foram adquiridos à taxa de $40 \mathrm{~Hz}$ (escala do modelo), guardados em formato digital e analisados através do software SAM.

\subsubsection{Avaliaçấo da estabilidade e galgamentos}

Para cada alternativa, a estabilidade do manto exterior foi analisada, em cada teste, através da contagem do número de quedas de blocos de enrocamento de 3 t a 6 t e da determinação da respetiva percentagem, calculada através da divisão daquele número pelo número total de blocos utilizado no modelo. Considerou-se que houve queda de um bloco sempre que este se movimentou da sua posição original numa distância igual ou superior ao seu diâmetro nominal.

O número de quedas de blocos por cada teste foi avaliado através da observação visual do modelo durante o teste, pela comparação de fotografias tiradas antes e depois do teste e pela análise do respetivo vídeo.

A percentagem de quedas de blocos foi comparada com a percentagem máxima aceitável de 5\% recomendada em CIRIA/CUR/CETMEF (2007), designada como a "inexistência de danos" ("no damage condition").

Para determinar os valores médios de caudais galgados por metro linear de estrutura, Q $(1 / \mathrm{s} / \mathrm{m})$, foi colocado um tanque de recolha de água a jusante da obra e a água era direcionada para o tanque através de uma rampa de $0,30 \mathrm{~m}$ de largura (Figura 6). Dentro do tanque instalaram-se uma bomba e um limnímetro, ligados a um computador que monitorizava e registava a variação de nível em cada ensaio
Tabela 3. Condiçóes nominais de ensaio na batimétrica $-4.1 \mathrm{~m}$ ODN (valores de protótipo).

Table 3. Target conditions at $-4.1 \mathrm{~m} O D N$ (prototype values).

\begin{tabular}{|c|c|c|c|}
\hline $\begin{array}{c}\text { Nível de Maré } \\
(m \text { ODN })\end{array}$ & $T_{o m}(s)$ & $H_{o s}(m)$ & Designação \\
\hline \multirow{4}{*}{3,5} & \multirow{4}{*}{8,5} & 2,5 & $\mathrm{TC1}$ \\
\hline & & 3,0 & TC2 \\
\hline & & 3,5 & TC3 \\
\hline & & 4,0 & $\mathrm{TC4}$ \\
\hline \multirow{4}{*}{4,0} & \multirow{4}{*}{7,5} & 2,5 & TC5 \\
\hline & & 3,0 & TC6 \\
\hline & & 3,5 & TC7 \\
\hline & & 4,0 & TC8 \\
\hline \multirow{4}{*}{4,8} & \multirow{4}{*}{8,0} & 2,5 & TC9 \\
\hline & & 3,0 & TC10 \\
\hline & & 3,5 & TC11 \\
\hline & & 4,0 & $\mathrm{TC} 12$ \\
\hline \multirow{4}{*}{5,8} & \multirow{4}{*}{5,6} & 1,8 & $\mathrm{TC} 13$ \\
\hline & & 2,0 & TC14 \\
\hline & & 2,5 & TC15 \\
\hline & & 3,0 & $\mathrm{TC} 16$ \\
\hline \multirow{2}{*}{4,8} & 7,0 & 2,7 & TC17 \\
\hline & 8,4 & 3,8 & $\mathrm{TC} 18$ \\
\hline \multirow{3}{*}{5,8} & 7,0 & 2,7 & TC19 \\
\hline & 7,5 & 3,0 & TC20 \\
\hline & 8,0 & 3,4 & $\mathrm{TC} 21$ \\
\hline \multirow{3}{*}{4,3} & 7,4 & 2,9 & TC22 \\
\hline & 8,0 & 3,4 & TC23 \\
\hline & 8,6 & 3,9 & TC24 \\
\hline \multirow{3}{*}{5,3} & 5,6 & 1,8 & TC25 \\
\hline & 7,4 & 2,9 & TC26 \\
\hline & 8,0 & 3,4 & TC27 \\
\hline
\end{tabular}

com uma frequência de $40 \mathrm{~Hz}$. Quando era atingido, no tanque, um nível máximo de água pré-estabelecido, a bomba era ativada por um período fixo de tempo. O volume de água bombada foi determinado com base na curva de calibração da bomba. A medição da variação do nível de água no tanque durante um ensaio, juntamente com a curva de calibraçáo da bomba, permitiam determinar os valores médios de caudais galgados por metro linear de estrutura, Q.

Os valores de $\mathrm{Q}$ obtidos para cada teste foram comparados com o valor máximo aceitável de $0,1 \mathrm{l} / \mathrm{s} / \mathrm{m}$ que tinha sido identificado como sendo adequado para os principais utilizadores da zona costeira protegida pela defesa longitudinal aderente (peôes e/ou veículos), de acordo com as atuais recomendaçóes disponíveis em Pullen et al. (2007).

\section{RESULTADOS}

\subsection{Caracterizaçáo da dinâmica da praia}

Os resultados da análise da evolução da posição da linha de costa entre 1956 e 2007 (Figura 7) mostram uma variação considerável da posição desta linha, tendo o valor máximo 
residual de deslocamento sido de 50 e $20 \mathrm{~m}$, de recuo e avanço, respectivamente (Figura 7A). O deslocamento médio da linha de costa foi de $13 \mathrm{~m}$ (recuo), correspondendo a uma área de cerca de $51 \times 10^{3} \mathrm{~m}^{2}$. Entre 1956 e 1980 praticamente toda a praia mostrou uma progressiva acreção, mais evidente no sector central. No período entre 1980 e 1990 ocorreu uma situação de recuo generalizado da linha de costa, com uma taxa média de erosão de $5 \mathrm{~m} \cdot \mathrm{ano}^{-1}$ e máxima perto de $8 \mathrm{~m}$. ano $^{-1}$ (Figura 7B). Esta situação terá estado associada a eventos de agitação marítima mais energéticos, que ocorreram entre 1988 e 1990, mas também à construçâo, nesse período, de estruturas de defesa costeira (quebra-mares de Rhos-on-Sea, Figura 1, e Penrhyn Bay, a Oeste do primeiro) que terão alterado a contribuiçẫo sedimentar à praia. Após este período, a praia mostrou uma recuperaçáo ligeira com taxas de acreção média e máxima entre 1990 e 2002 de
2 e 5 m.ano ${ }^{-1}$, respetivamente. Depois de 2002, verificou-se a sua estabilização, a uma taxa inferior a $0,5 \mathrm{~m} \cdot \mathrm{ano}^{-1}$. No período total de análise a praia perdeu, em área, cerca de $51 \times 10^{3} \mathrm{~m}^{2}$, da qual cerca de 50\% foi recuperada após 1990 .

A evoluçáo 3D da face da praia, entre Outubro 2001 e Novembro 2007, mostra a dominância do processo erosivo, com perda de sedimento da ordem de $40 \times 10^{3} \mathrm{~m}^{3}$, a uma taxa de $7 \times 10^{3} \mathrm{~m}^{3}$.ano ${ }^{-1}$, o que corresponde a um rebaixamento vertical médio de $15 \mathrm{~mm}$.ano ${ }^{-1}$ (Figura 8). Entre Outubro de 2001 e Maio de 2002 a taxa de erosão observada foi a mais elevada, igual a $49 \times 10^{3} \mathrm{~m}^{3}$.ano ${ }^{-1}$, seguindo-se a recuperação da praia na mesma ordem de grandeza. No entanto, as oscilaçóes volumétricas subsequentes promoveram a erosão geral da mesma. Os resultados mostraram que o sentido da variação volumétrica nem sempre está associado à sazonalidade do clima de agitação.

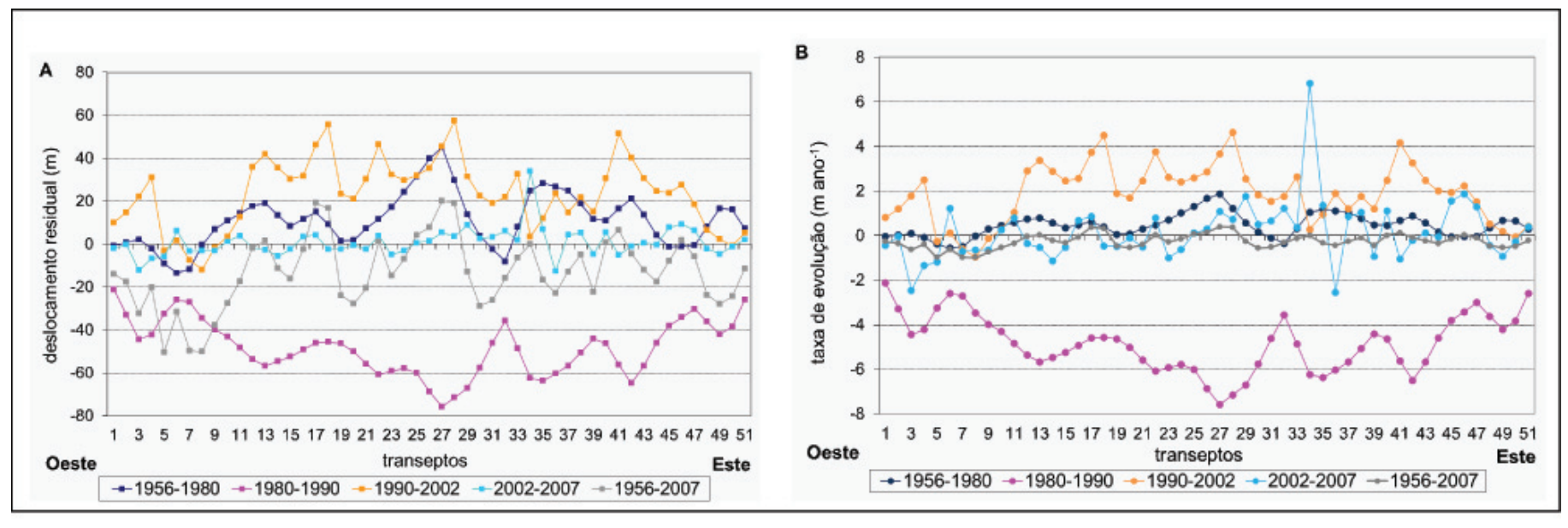

Figura 7. Deslocamento da linha de costa (A) e taxa de evolução (B) entre 1956 e 2007.

Figure 7. Shoreline displacement (A) and evolution rate (B) between 1956 and 2007.

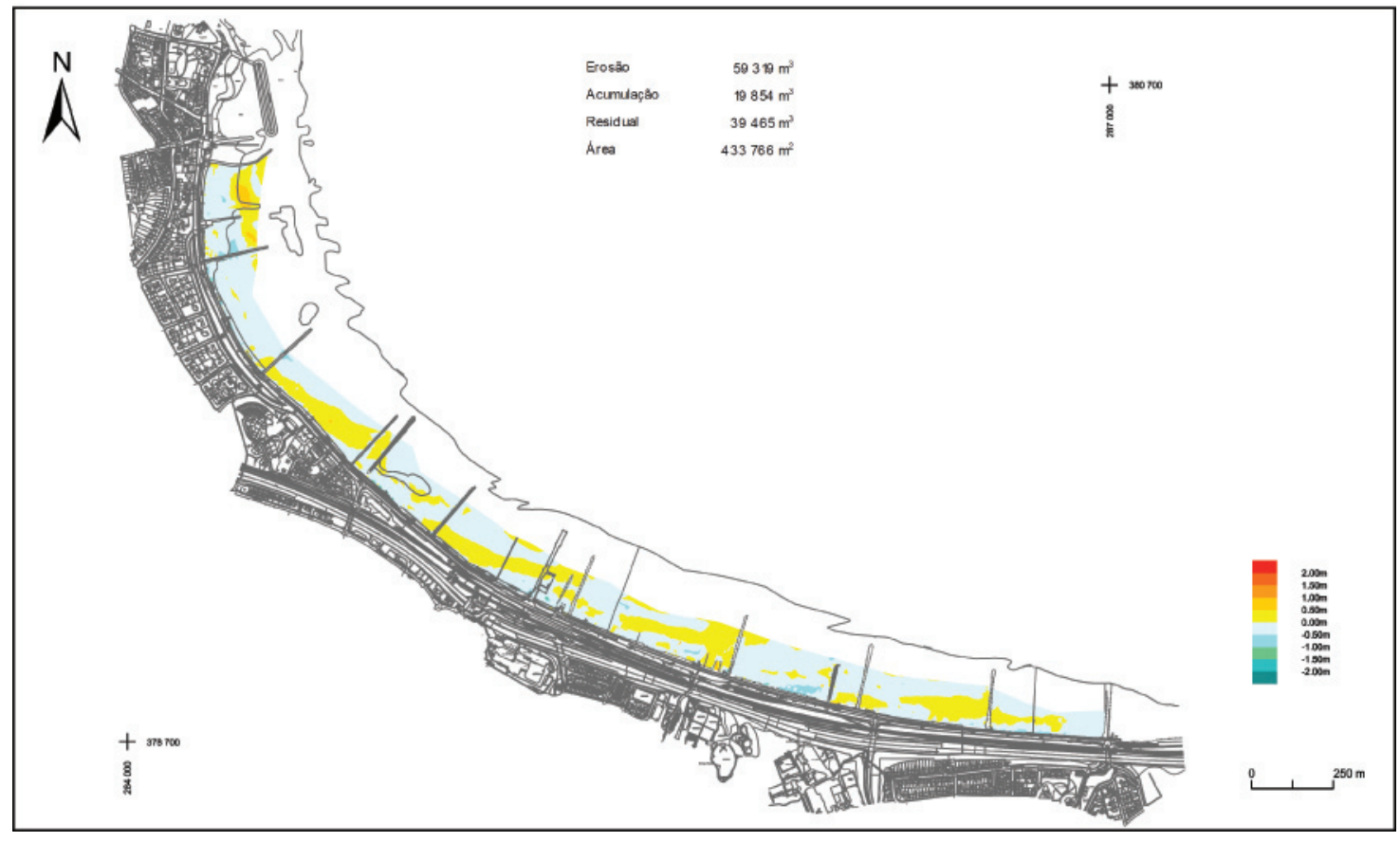

Figura 8. Evoluçáo da face da praia entre Outubro de 2001 e Novembro de 2007.

Figure 8. Evolution of the beach face between October 2001 and November 2007. 
A evolução vertical da zona superior da face de praia (na base da defesa longitudinal aderente) mostra que houve um rebaixamento longitudinal praticamente constante, com variação máxima entre 1984 e 1990, no valor de 1,6 m, e uma taxa de evolução de 0,2 m.ano ${ }^{-1}$ (Tabela 4). Os resultados para o período 1984-1988 refletem a acumulação observada no extremo Oeste da praia como consequência da construção do quebra-mar de Rhos-on-Sea. A evolução dos perfis transversais de praia evidencia a acentuada variabilidade morfológica dos mesmos, quer longitudinal, quer transversal. De um modo geral, os perfis que apresentam maior variabilidade morfológica são os dos extremos Oeste e Este, sendo a zona inferior da face de praia o sector onde a variação volumétrica é mais evidente. Não se observou uma correlação entre a variabilidade morfológica dos perfis e a sazonalidade do clima de agitação.

Os resultados da análise da composição sedimentológica mostraram que os sedimentos da praia de Colwyn Bay são principalmente areias. No entanto, encontra-se uma fração importante de material mais grosseiro (cascalho e blocos) na parte superior da face de praia ou em pequenas depressóes ao longo da zona inferior do perfil. No extremo Oeste, na zona protegida pelo quebra-mar de Rhos-on-Sea, sedimentos vasosos cobrem a zona inferior da face de praia e níveis de argila compacta afloram na zona inferior da face de praia, principalmente no seu extremo Este. $\mathrm{Na}$ zona superior da face da praia, as areias são grosseiras a cascalhentas, com $\mathrm{D}_{50}$ entre 0,6 e $3 \mathrm{~mm}$, e mal calibradas $(\sigma>3)$. Em alguns locais, os sedimentos são praticamente constituídos por bioclastos. $\mathrm{Na}$ zona inferior do perfil, as areias apresentam grão fino a médio $\left(D_{50}=0,2-0,3 \mathrm{~mm}\right)$ e são bem calibradas $(\sigma \sim 1)$. Para além da triagem granulométrica transversal, o diâmetro mediano dos sedimentos apresenta variabilidade longitudinal, com aumento do $\mathrm{D}_{50}$ nos extremos da praia, sectores com maior variabilidade morfológica, e particularmente em direção a Este. A densidade média das partículas é de 2,7.

Os resultados da análise do regime médio de agitação marítima ao largo (ver histogramas para a posição Central na Figura 9) mostraram que predominam os períodos de calmaria, com $\mathrm{Hs}<0,25 \mathrm{~m}$ e $2<\mathrm{Tz}<4$ s. As direçóes de agitação mais frequentes (somando $65 \%$ das ocorrências) são as compreendidas entre $285^{\circ}<\theta<345^{\circ}$, seguindo-se a agitação proveniente do quadrante Nordeste (totalizando 28\% das ocorrências). A altura de onda significativa máxima é inferior a $3,25 \mathrm{~m}$, oriunda da direção $\theta=0^{\circ}$, enquanto o valor médio de Hs é igual a $0,44 \mathrm{~m}(\mathrm{Tz}=3 \mathrm{~s})$.

Os resultados da análise de tempestades para 3 diferentes limiares de altura de onda $(\mathrm{H} s>2,0,2,5$ e 3,0 m) e quatro intervalos de duração da tempestade $(t<1,2$ e 3 dias, e $t>3$ dias) mostraram que ocorreram mais temporais no período entre 1987-1993 do que nos anos seguintes. A maior tempestade (maior Hs maior e mais longa duraçáo) ocorreu de 7 a 12 de Dezembro de 1990, secundada pela ocorrida de 26 de Fevereiro a 2 de Março de 1990, e utilizada para o dimensionamento do perfil ótimo da praia, devido à sua conjugação com níveis de água extremos.

Os resultados da análise do nível do mar a partir da série temporal (reconstituída) de 19 anos de níveis de água mostraram que o nível máximo estimado foi $5,2 \mathrm{~m}$, e os níveis de 4,0, 4,5 e 5,0 m ODN são somente excedidos, em média, 5 dias por ano, 1 dia por ano e 1 dia em 50 anos, respetivamente. Estes três níveis foram escolhidos para duas hipóteses de configuração da berma e perfil de enchimento. Determinou-se ainda a amplitude de maré modal (mais frequente), igual a $6,25 \mathrm{~m}$.

Os resultados da análise do transporte longitudinal na zona ativa submersa para os 19 anos de agitação marítima e nível do mar, entre 1987 e 2005, mostraram grande variaçâo interanual da capacidade de transporte sedimentar, entre $51,9 \times 10^{3}$ e $187,5 \times 10^{3} \mathrm{~m}^{3}$.ano ${ }^{-1}$ para a resultante do transporte (diferença entre as componentes dirigidas para Este e para Oeste) (Figura 10b). Constatou-se que existe uma predominância do transporte para Este, de cerca de 95\% do transporte total, tendo sido o valor médio do transporte para

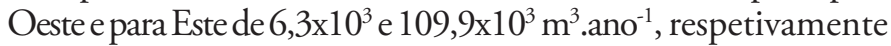
(Figura 10a). Como consequência, os transportes resultante e total (diferença e soma entre as duas componentes) médios foram bastante semelhantes: $103,5 \times 10^{3}$ e $116,3 \times 10^{3} \mathrm{~m}^{3}$. ano ${ }^{-1}$, respetivamente (Figura 10b). A análise da distribuição transversal do transporte longitudinal ao longo da zona ativa submersa mostrou que os valores médios da extensão transversal (ao longo do perfil) onde ocorre 90 e $95 \%$ do transporte total são 218 e $249 \mathrm{~m}$, respetivamente. As profundidades correspondentes são $-3,0$ e $-3,6 \mathrm{~m} \mathrm{ODN}$, respetivamente. Ao contrário da grandeza do transporte, estes parâmetros evidenciaram uma pequena variação interanual. Tal dever-se-á ao facto de dependerem maioritariamente da ocorrência de ondas com maior capacidade de transporte, as ondas com maior altura, que iniciam o seu processo de rebentação mais ao largo.

Os resultados descritos permitiram não só caracterizar a dinâmica da praia, conforme demonstrado, mas também foram fundamentais para a modelação das soluçóes alternativas, quer em perfil, quer em planta, pois foi com base neles que se estabeleceram as condiçóes geomorfológicas iniciais, de calibração e de verificação, e as condições

Tabela 4. Variação vertical da cota da praia na base da defesa longitudinal.

Table 4. Vertical variation of the beach level at the revetment base.

\begin{tabular}{lccccc}
\hline & $\mathbf{1 9 5 6 - 1 9 8 0}$ & $\mathbf{1 9 8 0 - 1 9 8 4}$ & $\mathbf{1 9 8 4 - 1 9 8 8}$ & $\mathbf{1 9 8 8 - 1 9 9 0}$ & $\mathbf{1 9 5 6 - 1 9 9 0}$ \\
\hline Média (m) & $-0,19$ & $-0,30$ & 0,12 & $-0,37$ & $-0,74$ \\
Rebaixamento máximo (m) & $-0,84$ & $-1,33$ & $-1,64$ & $-1,60$ & $-1,78$ \\
Taxa $\left(\right.$ m.ano $^{-1}$ ) & $-0,01$ & $-0,07$ & 0,03 & $-0,19$ & $-0,02$ \\
\hline
\end{tabular}



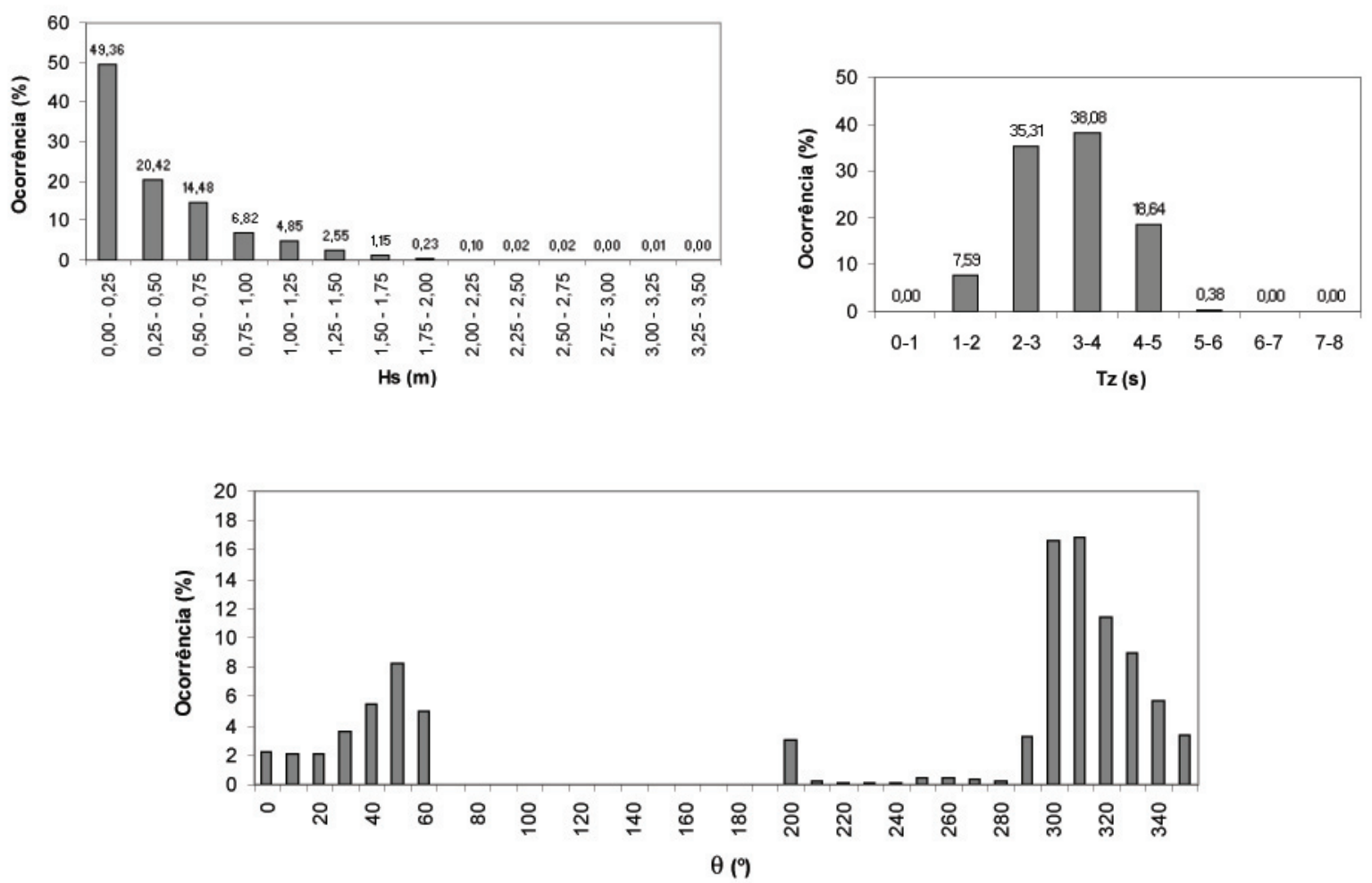

Figura 9. Histogramas de ocorrências de Hs, Tz e $\theta$.

Figure 9. Histogram of occurrance of $H s, T z$ and $\theta$.
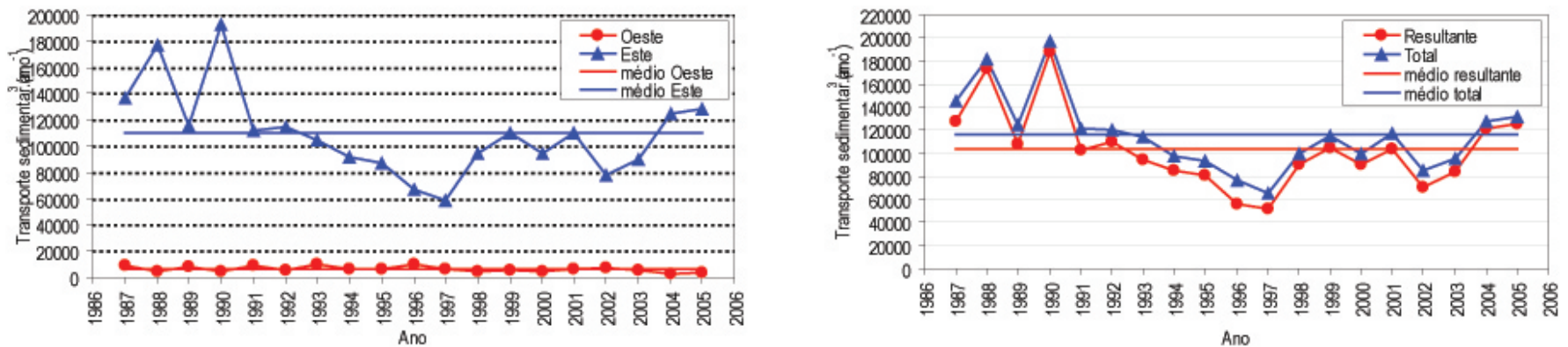

Figura 10. Capacidade de transporte longitudinal entre 1987 e 2005: a) dirigido para Oeste e Este; b) resultante e total. Figure 10. Longshore transport capacity between 1987 and 2005: a) towards West and East; b) net and total.

de hidrodinâmica que permitiram executar as previsóes do comportamento hidro-sedimentar da futura praia, apresentadas na secção seguinte.

\subsection{Soluçóes alternativas de reabilitaçáo e proteçáo da praia}

Estabelecidos os perfis de enchimento resultantes da combinação de duas configuraçôes para a berma (plana e inclinada) e cinco configuraçóes para o perfil (três do tipo 2S-EBP, para $\mathrm{D}_{50}=0,25,0,45$ e $0,75 \mathrm{~mm}$, e duas de declive constante), realizaram-se testes para a análise da morfodinâmica de curto prazo, nomeadamente para simular a ação erosiva das tempestades de Fev/1990 e Dez/1990,
Tabela 1. Os resultados da variação morfológica ao longo do perfil (Figura 11 e Tabela 5) mostraram que a tempestade de Fev/1990, em que os níveis do mar atingiram valores mais elevados, causou maior erosão (apesar das ondas terem cerca de metade da altura das ocorridas na tempestade de Dez/1990, Figura 4). A berma horizontal ao nível $4 \mathrm{~m}$ ODN permaneceu inalterada sob ação da tempestade de Dez/90 para os três testes efetuados (testes 1-3), nos quais apenas ocorreu erosão da face de praia (Figura 11a e Tabela 5). Contudo, sob ação da tempestade de Fev/90, a mesma berma (testes 4-5) foi quase totalmente erodida (Figura $11 \mathrm{~b}$ e Tabela 5). Constatou-se que a dispersão granulométrica, $\sigma$, é um parâmetro bastante influente na estabilidade do 

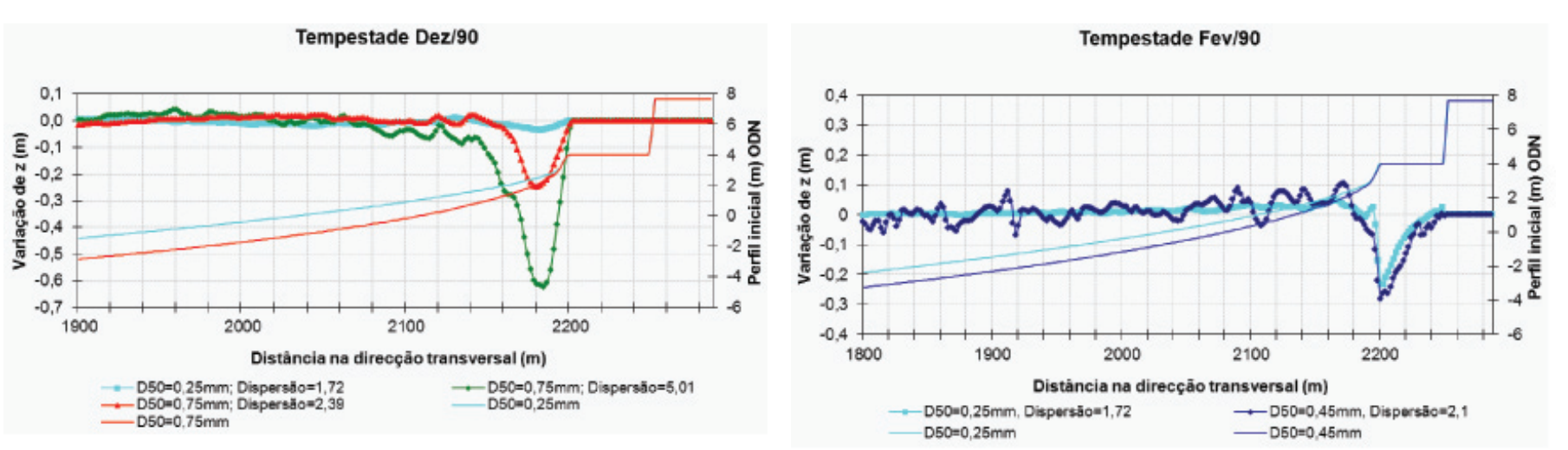

Tempestade Fev/90

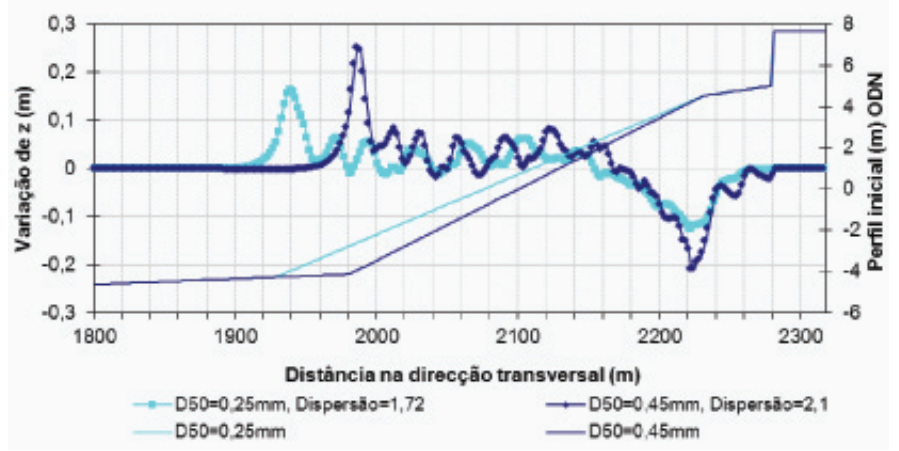

Figura 11. Evolução do perfil de enchimento a curto prazo para duas tempestades. Resultados dos testes: a) 1 a 3; b) 4 e 5; e c) 6 e 7. Figure 11. Short term evolution of the recharged beach profile for two sea storms. Results of the tests: a) 1 to 3; b) 4 and 5; and c) 6 and 7 .

Tabela 5. Parâmetros de morfodinâmica dos testes de evolução do perfil de enchimento a curto prazo.

Table 5. Morphodynamic parameters of the short term recharged beach profile evolution tests.

\begin{tabular}{|c|c|c|c|c|c|}
\hline Teste $n^{o}$ & $\begin{array}{c}\text { Condições sedimentológicas } \\
\qquad D_{50}(\mathrm{~mm}) ; \sigma(-)\end{array}$ & $\begin{array}{c}\text { Máximo } \\
\text { rebaixamento da } \\
\text { face de praia } \\
\text { (m) }\end{array}$ & $\begin{array}{c}\text { Distância do máximo } \\
\text { rebaixamento ao } \\
\text { paredão } \\
\text { (m) }\end{array}$ & $\begin{array}{c}\text { Volume de erosão } \\
\text { nos } 1^{\text {os }} 350 \mathrm{~m} \text { de } \\
\text { largura de praia } \\
\qquad\left(\mathrm{m}^{3}\right)\end{array}$ & $\begin{array}{c}\text { Recuo da } \\
\text { berma } \\
\text { (m) }\end{array}$ \\
\hline 1 & 0,$25 ; 1,72$ & 0,04 & 68 & 3 & 0 \\
\hline 2 & 0,$75 ; 5,01$ & 0,62 & 66 & 20 & 0 \\
\hline 3 & 0,$75 ; 2,39$ & 0,25 & 70 & 5 & 0 \\
\hline 4 & 0,$25 ; 1,72$ & 0,23 & 50 & 4,0 & 40 \\
\hline 5 & 0,$45 ; 2,10$ & 0,28 & 50 & 7,1 & 48 \\
\hline 6 & 0,$25 ; 1,72$ & 0,13 & 58 & 6,0 & 30 \\
\hline 7 & 0,$45 ; 2,10$ & 0,21 & 56 & 7,2 & 50 \\
\hline
\end{tabular}

perfil de praia. Os resultados numéricos indicaram que este parâmetro pode ser mais relevante do que o diâmetro mediano, $\mathrm{D}_{50}$, no processo de erosão. Concluiu-se que uma berma horizontal com $50 \mathrm{~m}$ de largura ao nível $4 \mathrm{~m}$ ODN é insuficiente para evitar a ação direta das ondas sobre o paredão, quando submetida à pior tempestade conhecida. Para estas condiçóes de estado do mar, apenas a berma de $50 \mathrm{~m}$ de largura e declive 1:100, implementada desde o nível $5 \mathrm{~m}$ ODN junto ao paredão até ao nível 4,5 $\mathrm{m}$ ODN, mostrou resiliência ao processo de erosão (Figura 11c e Tabela 5).
Salienta-se que, mesmo para esta geometria de topo de praia, apenas um perfil com pequena dispersão granulométrica, da ordem do valor aqui testado, $\sigma=1,72$, pode garantir uma largura mínima da berma de segurança.

Os resultados dos testes das soluçóes alternativas de longo prazo (para os 19 anos das séries de agitação marítima e nível do mar), ou seja, a evolução da forma plana da praia obtida com os modelos de evoluçáo da linha de costa, para as soluções baseadas em alimentação artificial sem estruturas de proteção, mostraram uma boa concordância entre os dois 


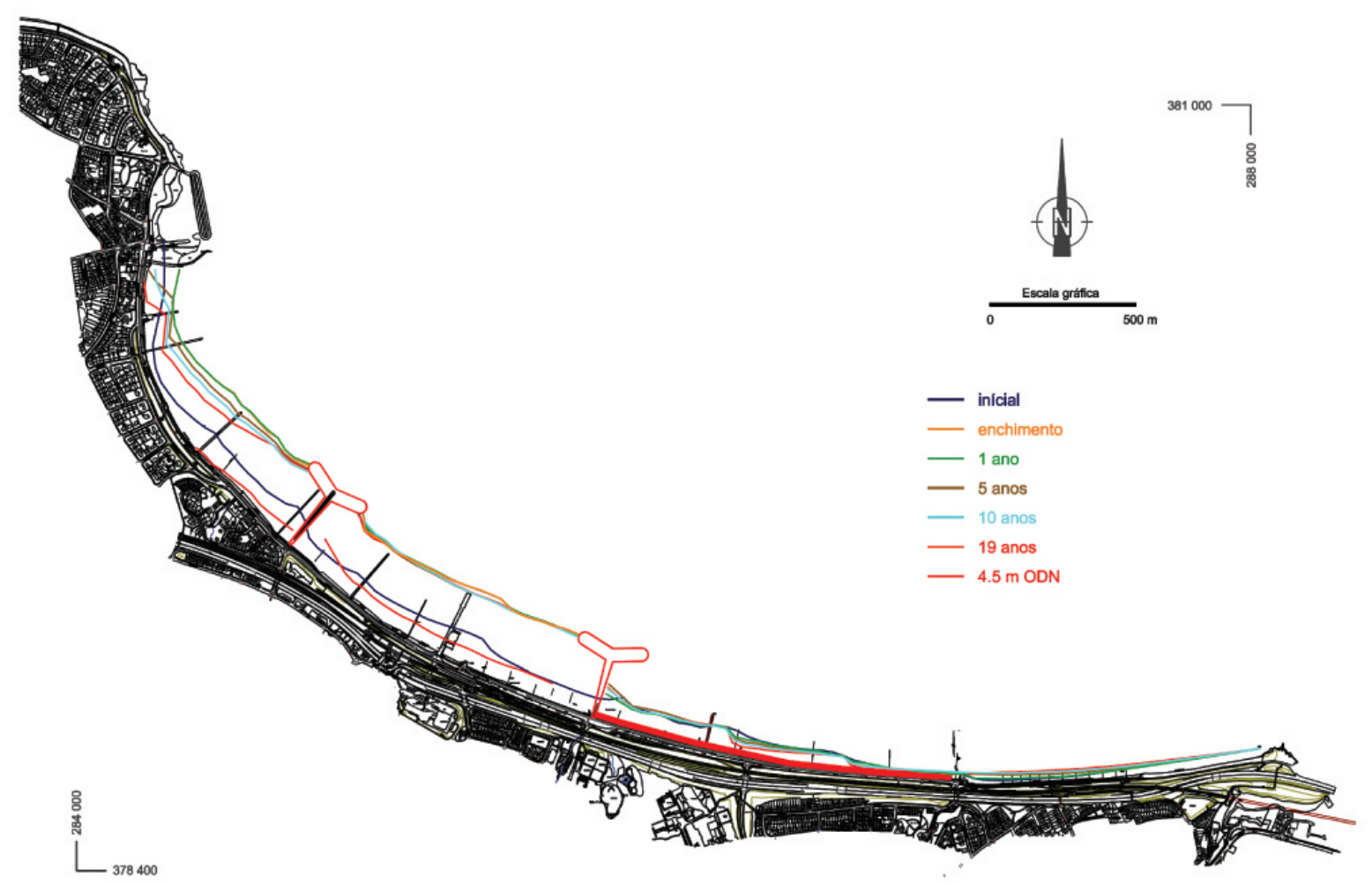

Figura 12. Simulação da evolução da linha de costa para a solução alternativa de alimentação artificial com dois esporóes em Y com $250 \mathrm{~m}$ de comprimento, distanciados de $1000 \mathrm{~m}$.

Figure 12. Shoreline evolution simulation for the alternative solution of beach nourishment with two fishtail groynes with $250 \mathrm{~m}$ length and $1000 \mathrm{~m}$ apart.

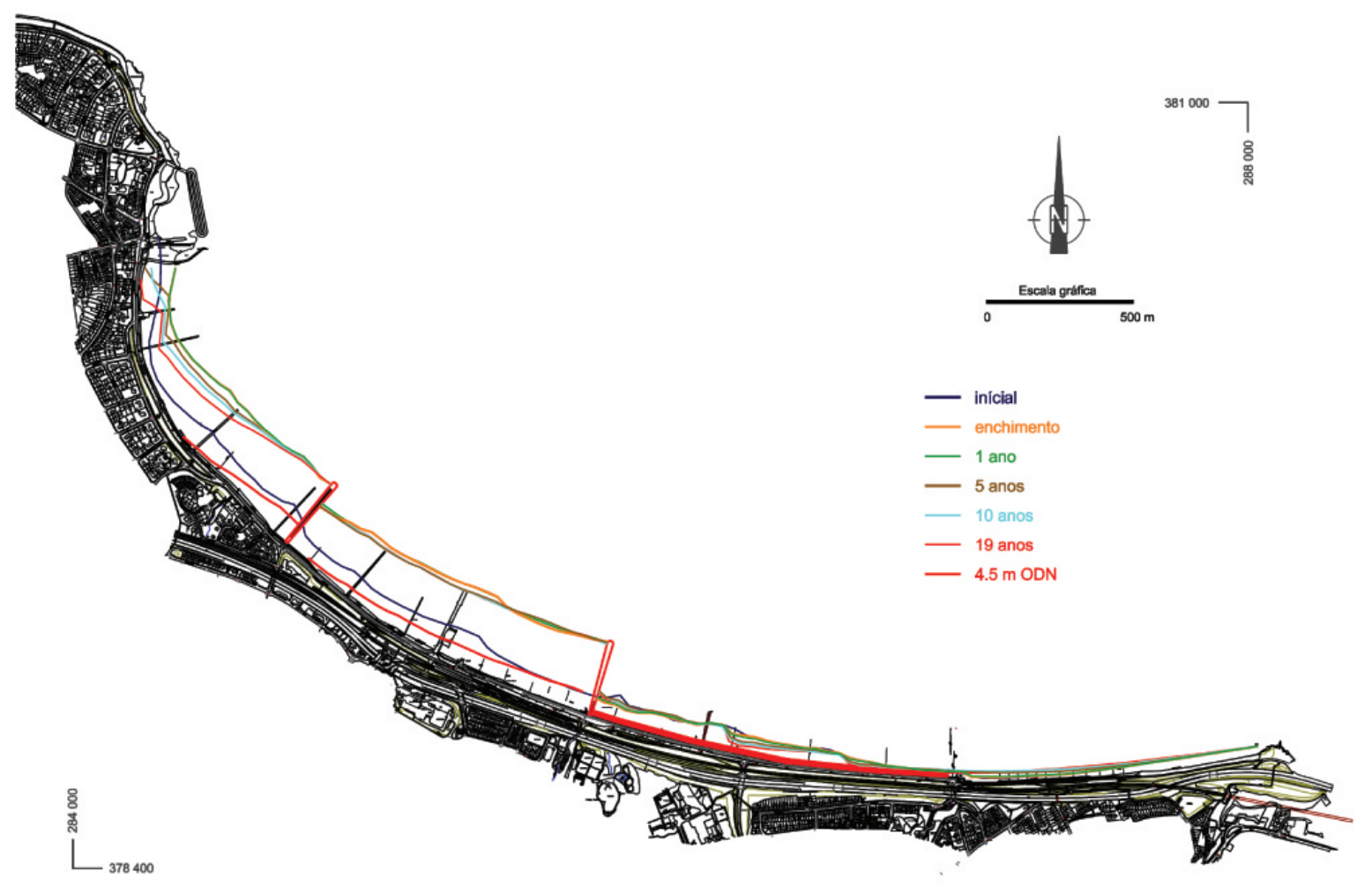

Figura 13. Simulação da evolução da linha de costa para a solução alternativa de alimentação artificial com dois esporóes com $250 \mathrm{~m}$ de comprimento, distanciados de $1000 \mathrm{~m}$.

Figure 13. Shoreline evolution simulation for the alternative solution of beach nourishment with two groynes with $250 \mathrm{~m}$ length and $1000 \mathrm{~m}$ apart. 


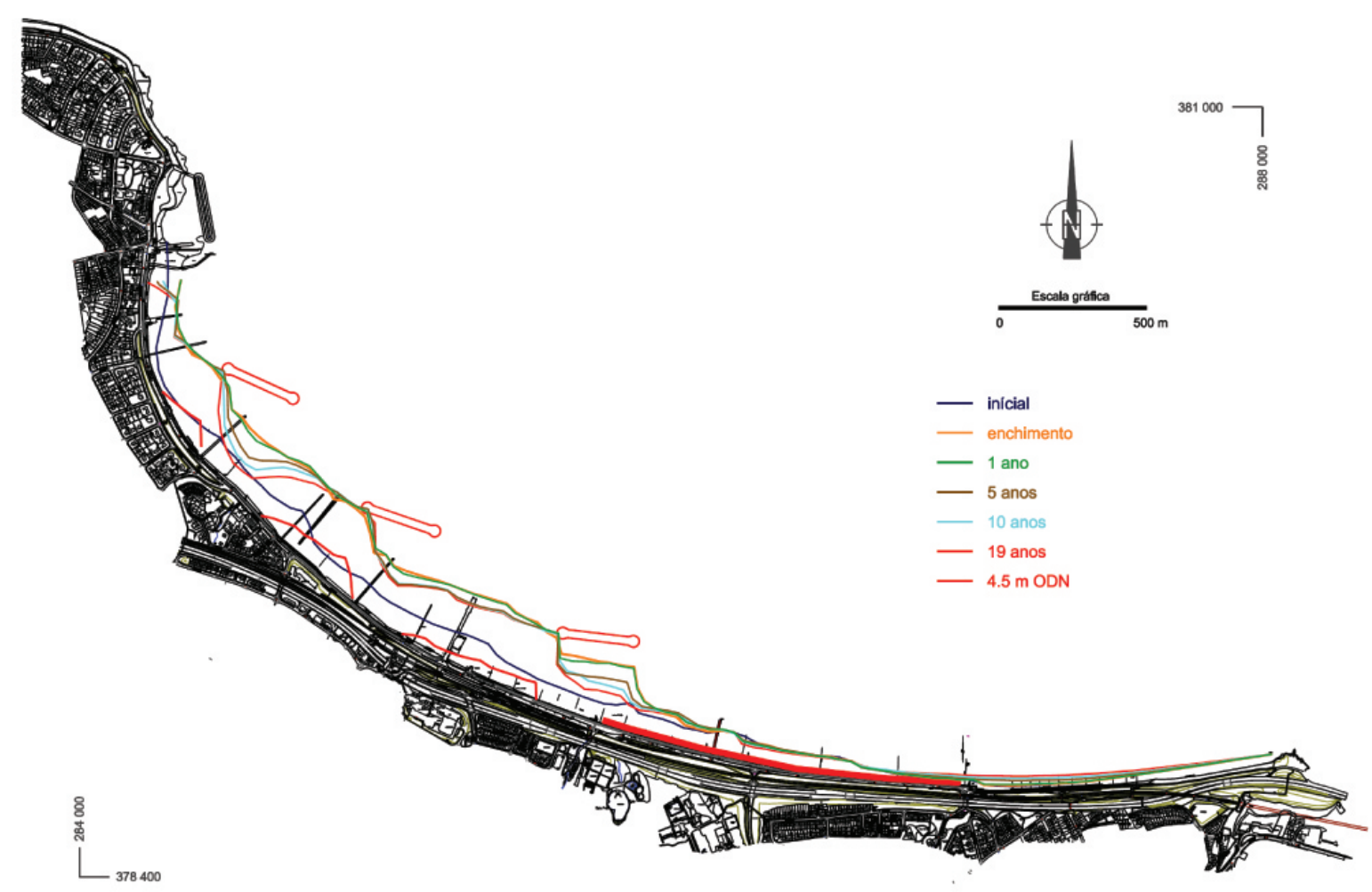

Figura 14. Simulação da evolução da linha de costa para a solução alternativa de alimentação artificial com três quebramares destacados com $280 \mathrm{~m}$ de comprimento.

Figure 14. Shoreline evolution simulation for the alternative solution of beach nourishment with three detached breakwaters with 280 m length.

modelos na previsão das perdas de sedimentos durante os primeiros 10 anos. Estimou-se uma perda de 17\% com o modelo Litline e $20 \%$ com o modelo Litmod, para ambos os casos (3,3 milhóes de $\mathrm{m}^{3}$ de areia com $\mathrm{D}_{50}=0,25 \mathrm{~mm}$ e 2,2 milhóes de $\mathrm{m}^{3}$ de areia com $\mathrm{D}_{50}=0,45 \mathrm{~mm}$ ). Ambos os modelos identificaram os extremos dos enchimentos como locais críticos de erosão (recuo da linha de costa) e o sector central como a zona mais estável. O extremo Este do enchimento foi o que mostrou maior recuo, $79 \mathrm{~m}$ com o modelo Litline para a solução de enchimento com $\mathrm{D}_{50}=0,25 \mathrm{~mm}$. Uma vez que o volume de enchimento considerando $\mathrm{D}_{50}=0,25 \mathrm{~mm}$ é superior ao volume para $\mathrm{D}_{50}=0,45 \mathrm{~mm}$, a perda de sedimentos é superior, logo, o enchimento com $\mathrm{D}_{50}=0,45 \mathrm{~mm}$ seria potencialmente mais económico.

Com o objetivo de diminuir as perdas de areia ao longo do tempo verificadas nas soluçóes alternativas anteriores, testaram-se os seguintes arranjos baseados em alimentação artificial e obras fixas de contenção: i) um esporão em Y com $250 \mathrm{~m}$ de comprimento; ii) dois esporóes em Y com $250 \mathrm{~m}$ de comprimento, distanciados de 1000 m (Figura 12); iii) dois esporóes com $250 \mathrm{~m}$ de comprimento, distanciados de $1000 \mathrm{~m}$ (Figura 13); iv) três quebra-mares destacados com $280 \mathrm{~m}$ de comprimento (Figura 14); v) dois esporôes em Y com $250 \mathrm{~m}$ de comprimento, distanciados de $1600 \mathrm{~m}$. Estas soluçóes foram avaliadas e comparadas qualitativa e quantitativamente. Os parâmetros qualitativos foram: partição da praia, uniformidade da largura de praia, aproveitamento de estruturas existentes, segurança para uso recreativo, vista para o mar e provável ocorrência de problemas associados a sedimentação (incluindo de salubridade). A solução minimalista (em termos de implementação de estruturas), que consistiu na implementação de esporōes, alternativa iii), é a que oferece condiçóes mais compatíveis com a futura utilização da praia, que será prática balnear, de desportos náuticos, passeios com vista para o mar e outros tipos de uso recreativo. Os parâmetros quantitativos usados para avaliar e comparar as soluçóes alternativas foram: a posição da linha de costa após 1, 5, 10 e 19 anos de simulação, a posição do topo do 2S-EBP (linha ao nível 4,5 m ODN) após 10 anos, e a perda de sedimentos do trecho de enchimento após 10 anos. Os principais resultados foram:

- Ao fim de 10 anos, a perda de sedimentos correspondente ao enchimento variou apenas $3 \%$ entre as soluçóes alternativas (entre 17 e 20\%);

- A pior solução foi a alternativa iv), com $20 \%$ do enchimento perdido ao fim de 10 anos. A linha de costa, que ao fim de 5 anos já se apresentava bastante irregular, continuou a recuar na parte central e no extremo Este de cada quebra-mar destacado até ao final da simulação. $\mathrm{O}$ elevado recuo do perfil de praia nestas localizaçóes poderá causar erosão se for exercida uma ação direta da onda sobre o paredão devido à ausência de berma;

- O esporão em forma de Y é mais eficiente em reter areia na sua área adjacente, particularmente na zona de abrigo 


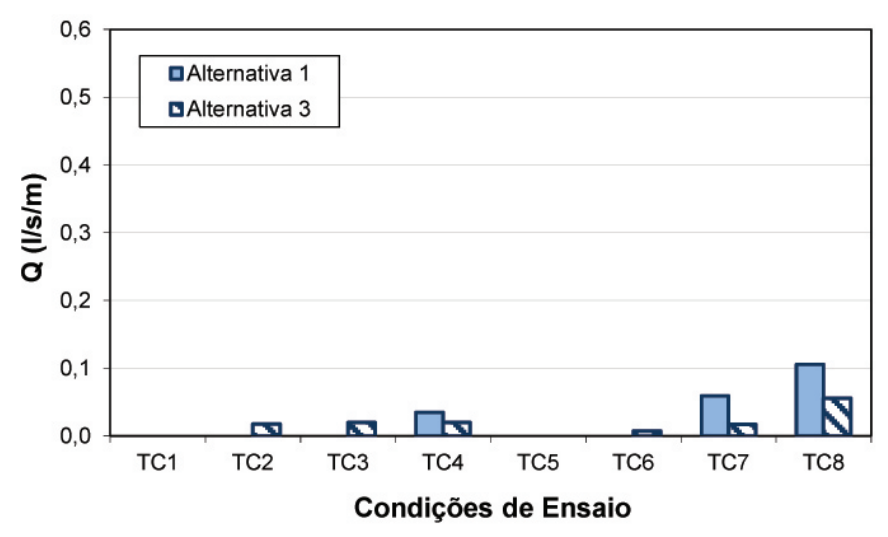

Figura 15. Valores médios de caudais de galgamento por metro linear de estrutura, Q, obtidos para os níveis de maré 3,5 m ODN (TC1 a TC4) e 4,0 m ODN (TC5 a TC8).

Figure 15. Mean overtopping discharges, $Q$, obtained for the still-waterlevels of $3.5 \mathrm{~m} O D N$ (TC1 to TC4) and $4.0 \mathrm{~m}$ ODN (TC5 to TC8).

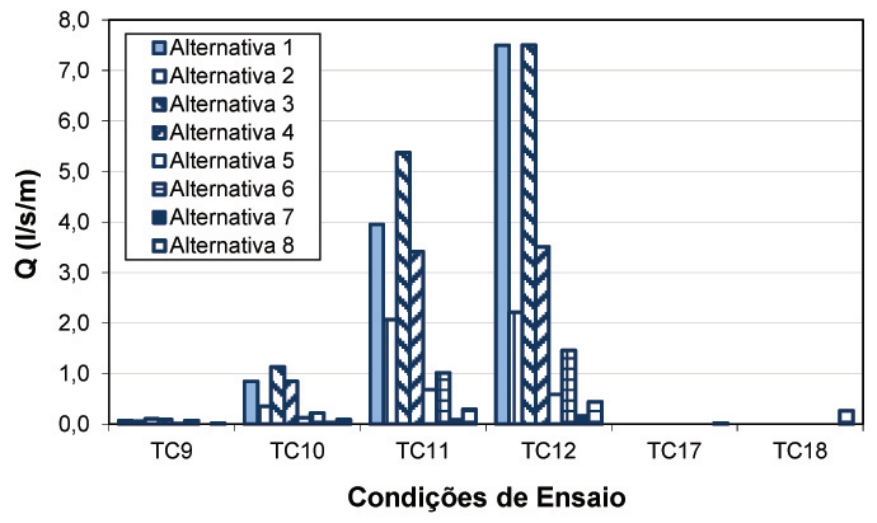

Figura 16. Valores médios de caudais de galgamento por metro linear de estrutura, Q, obtidos para o nível de maré 4,8 m ODN (TC9 a TC12, TC17 e TC18).

Figure 16. Mean overtopping discharges, $Q$, obtained for the stillwater-level of $4.8 \mathrm{~m}$ ODN (TC9 to TC12, TC17 and TC18).

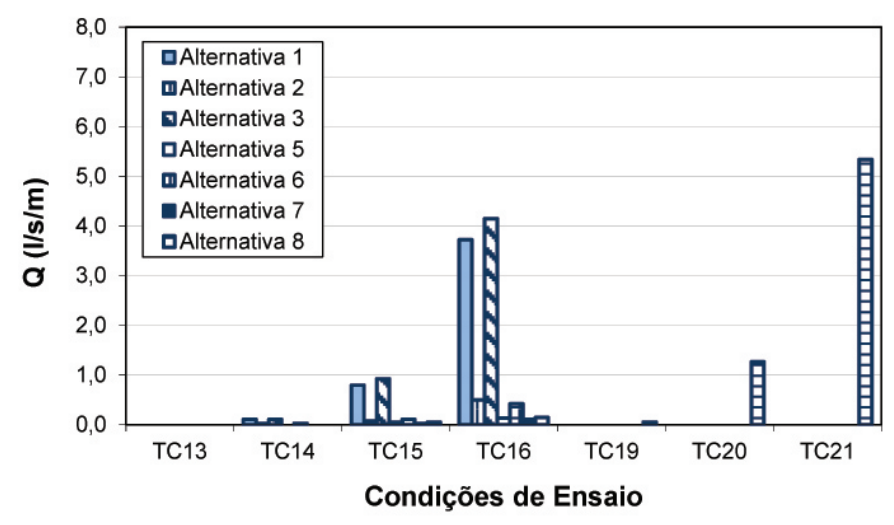

Figura 17. Valores médios de caudais de galgamento por metro linear de estrutura, Q, obtidos para o nível de maré 5,8 m ODN (TC13 a TC16 e TC19 a TC21).

Figure 17. Mean overtopping discharges, $Q$, obtained for the stillwater-level of $5.8 \mathrm{~m}$ ODN (TC13 to TC16 and TC19 to TC21).

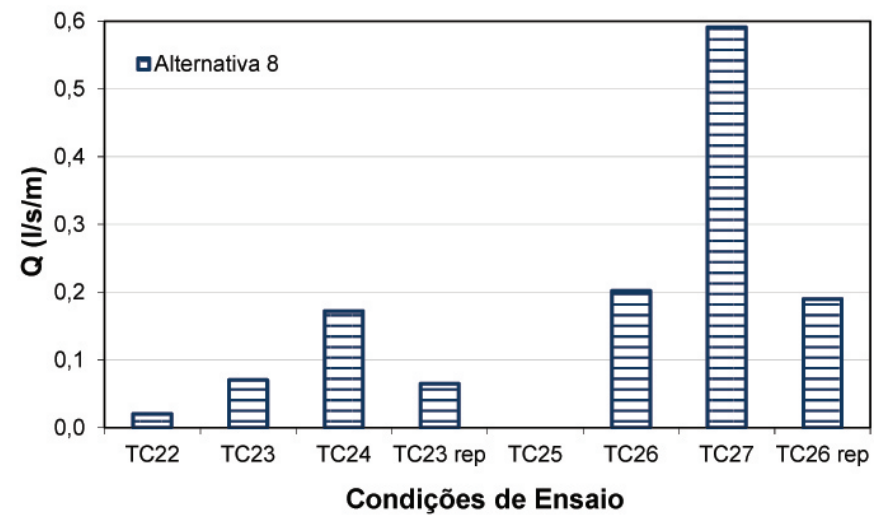

Figura 18. Valores médios de caudais de galgamento por metro linear de estrutura, $\mathrm{Q}$, obtidos para os níveis de maré 4,3 m ODN (TC22 a TC24 e repetição de TC23) e 5,3 m ODN (TC25 a TC27 e repetição de TC26).

Figure 18. Mean overtopping discharges, $Q$, obtained for the stillwater-levels of $4.3 \mathrm{~m}$ ODN (TC22 to TC24 and repetition of TC23) and $5.3 \mathrm{~m} O D N$ (TC25 to TC27 and repetition of TC26). 
da estrutura, o lado Este, do que o esporão com o mesmo comprimento (comparando alternativas ii) e iii));

- O deslocamento para Oeste do esporão em Y localizado a Oeste reduz a uniformidade da largura de praia no trecho entre os esporóes em Y, em particular no lado Este desse esporão (comparando alternativas ii) e v)).

Também foram testadas as três primeiras alternativas considerando um aumento de $50 \mathrm{~m}$ no comprimento das estruturas transversais. Os resultados mostraram que a perda de areia ao fim de 10 anos foi reduzida para 12\% do volume de enchimento, para os três casos. Este melhoramento deve-se ao facto da profundidade de fecho ser maior (situar-se mais ao largo) do que a profundidade a que se localizam os extremos destas estruturas, e consequentemente o seu prolongamento causar um aumento significativo da capacidade de retenção.

\subsection{Solução para reabilitaçáo da defesa aderente}

No que diz respeito à estabilidade do manto resistente de enrocamento, os ensaios em modelo físico mostraram que as Alternativas 1 a 8 eram muito estáveis: a percentagem de quedas de blocos de enrocamento foi sempre inferior a $1 \%$. Quando ocorreram estragos, estes limitaram-se à camada superior do manto, não ficando os filtros visíveis em qualquer situação. Durante o decurso dos ensaios, considerou-se que seria possível diminuir o peso do enrocamento sem comprometer a estabilidade da estrutura, embora esta situação não tivesse sido testada.

As Figuras 15 a 18 apresentam os valores dos caudais de galgamento das 8 alternativas ensaiadas para os seis níveis de maré testados. As figuras mostram que o nível de maré 4,8 m ODN foi, para todas as alternativas consideradas, o menos favorável no que diz respeito ao galgamento. Quando se consideram os valores dos caudais de galgamento obtidos com as Alternativas 1 e 2 , verifica-se que na primeira delas o galgamento excedeu, por uma margem considerável, o critério aceitável de $0,1 \mathrm{l} / \mathrm{s} / \mathrm{m}$. No entanto, a observação visual do modelo mostrou que o muro-cortina era muito eficaz a limitar o volume de água associados aos galgamentos. $\mathrm{Na}$ Alternativa 2, o aumento da altura do muro-cortina em $0,5 \mathrm{~m}$ para um valor igual a $8,5 \mathrm{~m}$ ODN, reduziu de uma forma muito significativa os níveis de galgamento, apesar de ainda se manterem acima do critério exigido para os testes TC10 a TC12 e para TC16 (ver Tabela 3 e Figura 15). O aumento da cota de coroamento do muro-cortina melhorou o nível de serviço, que passou de menos de 50 anos para entre 50-100 anos, se não for considerada a subida do nível médio do mar, e de 10 anos para mais de 20 anos se for considerada a subida do nível do mar prevista para os próximos 75 anos, segundo as atuais recomendaçóes da DEFRA (2006).

Os resultados das Alternativas 3 e 4 demonstraram que um talude mais inclinado, de 1:2,5, com uma berma de betão mais larga em frente ao muro-cortina não foi tão eficaz a reduzir os galgamentos como o talude mais suave, de 1:3, com uma berma de betão mais estreita.

Os resultados da Alternativa 5 mostraram que uma berma de enrocamento mais larga foi eficaz na redução dos galgamentos. Esta alternativa proporcionou um desempenho muito semelhante ao da Alternativa 2, com um nível de serviço acima de 50 anos, sem ter em consideração a subida do nível do mar, descendo para 20-50 anos se for considerada a subida do nível do mar prevista para os próximos 75 anos.

Nas Alternativas 6 e 7 (que não continham a laje de betão no coroamento), foi necessário que a berma de enrocamento estivesse à cota $9 \mathrm{~m} \mathrm{ODN}$, com um muro deflector de $1 \mathrm{~m}$ de altura (cota de coroamento igual a $10 \mathrm{~m}$ ODN) para que fosse possível manter o nível de galgamentos dentro do critério exigido, o que pode vir a revelar-se problemático na sua integração com os atuais arranjos propostos para a zona adjacente à costa. $\mathrm{Na}$ Alternativa 7 , apesar dos níveis de galgamento terem excedido o critério exigido em TC12 e TC16 e do vento não ter sido reproduzido no modelo, os galgamentos verificados foram considerados aceitáveis, já que apenas ultrapassaram por uma pequena margem o valor limite de galgamento.

Na Alternativa 8, a eficácia do talude mais suave, do murocortina deflector e da berma de coroamento permeável (de enrocamento) foi utilizada para tentar reduzir os galgamentos para valores aceitáveis, mantendo, em simultâneo, as cotas de coroamento tão reduzidas quanto possível. Os níveis de galgamento excederam o critério exigido em TC11, TC12, TC16, TC18, TC20, TC21, TC24, TC26 e TC27. A Alternativa 8 proporcionaria um nível de serviço acima de 50 anos se não for levada em consideração a subida do nível do mar, ou de 20-50 anos se for considerada a subida do nível do mar prevista para os próximos 75 anos.

De todos os perfis testados, a Alternativa 7 foi aquela que apresentou o melhor desempenho relativamente aos galgamentos. Em geral, proporcionaria um nível de serviço de 100 anos se não forem levadas em consideração futuras subidas do nível do mar, ou de 50 anos se forem consideradas as subidas do nível do mar previstas nos próximos 75 anos.

\section{CONCLUSÓES E RECOMENDAÇÓES}

A componente relativa à modelação numérica do estudo para a reabilitação e proteção da praia de Colwyn Bay teve como objetivo a definição de soluçóes alternativas baseadas em alimentação artificial e foi dividida em duas partes: a caracterização da dinâmica da praia e o teste de soluçóes alternativas. Esta última parte baseou-se na otimização do perfil de enchimento e na previsão da evolução da linha de costa a longo prazo para as soluçóes alternativas. No âmbito da caracterização da dinâmica da praia foram processados, produzidos e analisados dados geomorfológicos e de hidrodinâmica que também foram usados como dados iniciais e de verificação/controlo para os modelos numéricos aplicados, quer na otimização do perfil de enchimento, quer no teste das soluçóes alternativas de longo prazo.

As principais conclusóes e recomendaçóes desta componente do estudo foram:

- O enchimento da praia deve contemplar um volume que garanta uma largura de berma de segurança que evite a ação direta das ondas sobre a defesa longitudinal aderente durante a ocorrência de tempestades. Por isso, recomenda-se a implementação de uma berma com declive 1:100 entre o nível 5 e 4,5 m ODN, seguida de um perfil do tipo $2 \mathrm{~S}$-EBP.

- Das soluções alternativas baseadas em alimentação artificial com estruturas de retenção testadas, as que 
tiveram melhor desempenho na retençáo do enchimento foram as baseadas em estruturas normais à praia, e, entre estas, a que oferece maior garantia de retenção do volume de enchimento e simultaneamente oferece condições compatíveis com o futuro uso da praia é a alternativa ii), dois esporóes em Y com $250 \mathrm{~m}$ de comprimento, distanciados de $1000 \mathrm{~m}$.

- O aumento de $50 \mathrm{~m}$ do comprimento dos esporóes das alternativas i), ii) e iii) beneficiaria a redução da perda de sedimentos, que ao fim de 10 anos passaria de 18 para $12 \%$ do enchimento total.

- A monitorização da morfologia da praia, desde a defesa longitudinal aderente até ao limite da futura zona ativa da praia submersa (aproximadamente $-5 \mathrm{~m}$ ODN), deve ser realizada durante e depois do projeto, pois não só permitirá a avaliação do seu desempenho, mas também a quantificação das transferências transversais e longitudinais de sedimentos, e assim, alertar no caso de ocorrerem situaçóes atípicas ou fora do esperado.

- A comparação de soluções alternativas foi realizada com base numa análise estritamente técnica. Por isso, recomenda-se a realizaçáo de uma análise de custo-benefício para suportar a escolha da solução mais sustentável.

A componente relativa à modelação física do estudo para a reabilitação e proteção da praia de Colwyn Bay teve como objetivo examinar a eficácia e definir configuraçôes para a nova defesa longitudinal com base em ensaios em modelo físico para a análise da estabilidade e galgamentos das secçōes transversais alternativas previstas para o extremo Este de Colwyn Bay. Ensaiou-se uma ampla gama de combinaçóes de características da agitação marítima e níveis de maré, com 1 a 200 anos de período de retorno. Foram consideradas oito configuraçóes diferentes (Alternativas 1 a 8 ) da secção transversal da defesa longitudinal, com diferentes inclinaçóes do talude do manto exterior, diversas geometrias e permeabilidade da berma de coroamento e distintas geometrias do muro-cortina.

As principais conclusōes e recomendaçôes desta componente do estudo foram:

- O manto exterior, composto por duas camadas de blocos de enrocamento de 3 t a 6 t, com um declive de 1:2,5 ou de 1:3, e com um filtro de uma camada de blocos de enrocamento de $300 \mathrm{~kg}$ a $1 \mathrm{t}$, mostrou-se uma estrutura estável que provisiona uma proteção adequada.

- No que respeita aos galgamentos, para o tipo de alternativas testadas, a combinaçẫo entre uma menor inclinação de talude, um muro-cortina deflector e um coroamento permeável foi a que apresentou maior eficácia na redução dos galgamentos. Assim, a Alternativa 7 foi aquela em que a estrutura sofreu menos galgamentos, seguida das Alternativas 8 e 5 .

- Tendo em conta a relaçáo entre o custo de construção das estruturas e o critério económico definido para o investimento, as Alternativas 1, 2 e 8 foram consideradas as mais adequadas para a zona em estudo, uma vez que seriam aquelas que melhor se interligariam com os arranjos propostos para a zona adjacente à linha de costa, garantindo também uma adequada proteçâo costeira.

- A decisão final sobre o perfil de defesa mais adequado para a zona em estudo deve contemplar, em termos de projeto, aspetos adicionais, em particular a relação entre o nível de risco que é considerado aceitável e os custos adicionais necessários para proporcionar diferentes níveis de proteção.

\section{AGRADECIMENTOS}

Os autores agradecem aos técnicos Dr. Lourival Trovisco, Sr. Luís Simóes Pedro, Sr. Victor Pisco, Sr. Fernando Brito, Eng. Ana Passarinho e Eng. Odair Maurício pela contribuição dada neste estudo, ao Conwy County Borough Council, pelo financiamento do estudo e autorização de publicação, e à Royal Haskoning, Reino Unido, pelo consórcio estabelecido e pela colaboração na definição das soluçôes alternativas do perfil transversal da defesa longitudinal aderente e do seu programa de ensaios em modelo físico.

\section{BIBLIOGRAFIA}

Bernabeu, A.M.; Medina, R.; Vidal, C. (2003) - A morphological model of the beach profile integrating wave and tidal influences. Marine Geology, 197(1-4):95116. doi:10.1016/S0025-3227(03)00087-2.

Capitão, R. (2002) - Modelação estocástica numérica e física da agitação marítima. 434p., Tese de Doutoramento, Instituto Superior Técnico, Lisboa, Portugal. Não publicado.

CCBC (2007) - Colwyn Bay Coastal Defence Strategy Plan. Stage 2: Strategic Assessment and Proposals - Draft for Consultation. 8p., Conwyn County Borough Council, Wales. http://www.conwy.gov.uk/upload/public/ attachments/311/English_CBSP_Stage_2_Strategic_ Assessment_Exec_Summary_Draft_for_Consultation_ Nov_07.pdf.

CIRIA/CUR/CETMEF (2007) - The Rock Manual: C683 - The Use of Rock in Hydraulic Engineering (2nd edition). 1304p., CIRIA - Construction Industry Research \& Information Association, CUR - Centre For Civil Engineering, Londres, Reino Unido. ISBN: 9780860176831 .

de Rouck, J.; Geeraerts, J.; Troch, P.; Kortenhaus, A.; Pullen, T.; Franco, L. (2005) - New results on scale effects for wave overtopping at coastal structures. Proceedings of Coastlines, Structures \& Breakwaters '05, pp. 29-43, ICE, Thomas Telford, Londres, Reino Unido.

DEFRA (2006) - Flood and Coastal Defence Project Appraisal Guidance, FCDPAG3 Economic Appraisal - Supplementary Note to Operating Authorities - Climate Change Impacts. 9p., DEFRA - Department for Environment, Food and Rural Affairs, Reino Unido, Disponível em http://archive.defra. gov.uk/environment/flooding/documents/policy/guidance/ fcdpag/fcd3climate.pdf.

DHI (2008) - Litpack. Noncohesive Sediment Transport in Currents and Waves. User Guide. Danish Hydraulic Institute, Hørsholm, Dinamarca.

HRWallingford (2004) - Conwy TidalFloodRiskAssessment-Stage 1 Report. Report EX 4667 (release 3.0), s/p., Conwy, País de Gales, Reino Unido. Disponível em http://conwyfloodmap. 
hrwallingford.co.uk/report/HRWallingford_ConwyFRA_ Stage1_Report_EX4667.pdf

Hughes, S.A. (1993) - Physical Models and Laboratory Techniques in Coastal Engineering. 568p., Advanced Series on Ocean Engineering - Vol. 7, World Scientific, Singapura. ISBN 981-02-1540-1.

Kamphuis, J.W. (1991) - Alongshore sediment transport rate. Journal of Waterway, Port, Coastal and Ocean Engineering, 117(6):624-640. doi 10.1061/(ASCE)0733950X(1991)117:6(624)

Pawlowicz, R.; Beardsley, B.; Lentz, S. (2002) - Classical Tidal Harmonic Analysis Including Error Estimates in MATLAB using T_TIDE. Computers and Geosciences, 28(8):929-937. doi: 10.1016/S0098-3004(02)00013-4.

Pullen, T.; Allsop, N.W.H.; Bruce, T.; Kortenhaus, A.; Schuttrumpf, H.; Van der Meer, J.W. (2007) - EurOtop: Wave Overtopping of Sea Defences and Related Structures: Assessment Manual. 178p., Environment Agency, Reino Unido, Expertise Netwerk Waterkeren, Holanda e Kuratorium fur Forschung im Kusteningenieurwesen, Alemanha. ISBN: ISBN 978-3-8042-1064-6. http://www. overtopping-manual.com/eurotop.pdf

Reis, M.T.; Neves, M.G.; Silva, L.G.; Williams, A.; Hu, K.; Winfield, P. (2010) - Physical model tests of new linear defences for Colwyn Bay. Proceedings 3rd International Conference on the Application of Physical Modelling to Port and Coastal Protection, CoastLab10, Barcelona, Espanha. Disponível em http://www.coastlab10.com.
Thieler, E.R.; Himmelstoss, E.A.; Zichichi, J.L.; Ergul, A. (2009) - Digital Shoreline Analysis System (DSAS) version 4.0 - An ArcGIS extension for calculating shoreline change. U.S. Geological Survey Open-File, Report 2008-1278, Woods Hole Coastal and Marine Geology Team, Woods Hole, MA, U.S.A. Disponível em http://woodshole. er.usgs.gov/project-pages/dsas/version4/

Troch, P. (2005) - User Manual: Active Wave Absorption System. 43p. Gent University, Department of Civil Engineering, Gent, Bélgica.

Vicente C.M.; Clímaco, M. (2003) - Evolução de Linhas de Costa. Desenvolvimento e Aplicação de um Modelo Numérico. 167p. ICT/ITH-42, LNEC - Laboratório Nacional de Engenharia Civil, Lisboa, Portugal.

Vicente, C.M. (1991) - Aperfeiçoamento de Métodos de Modelação Matemática e Física Aplicáveis a Problemas de Dinâmica Costeira. 147p., LNEC - Laboratório Nacional de Engenharia Civil, Lisboa, Portugal. 